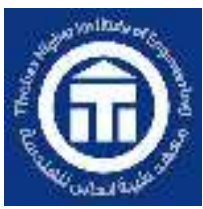

INTERNATIONAL JOURNAL OF ADVANCED ENGINEERING

AND BUSINESS SCIENCES (IJAEBS)

Journal homepage: International Journal of Advanced Engineering and Business Sciences (ekb.eg)

\title{
Irradiance Sudden Change Grid Connected Fuzzy Self Tuning PID Controller Maximum Power Point Tracking Technique for Photovoltaic Power System
}

\author{
Mohammed F. Gabra*, Soliman M. Sharafb, Helmy M.Elzoghbyc \\ a Power Department, Faculty of Engineering, Helwan University, Cairo, Egypt. \\ b Power Department, Faculty of Engineering, Helwan University, Cairo, Egypt \\ c Power Department, Faculty of Engineering, Helwan University, Cairo, Egypt \\ * The corresponding author: E-mail: eng.m.gabr@gmail.com
}

\section{ABSTRACT}

This paper presented the Deep detail of ANFIS and Grid Connected. Photovoltaic power generation system required an effective controller to overcome sudden irradiance change and to maximize their efficiency in order to be more efficient \& more precise. This paper proposed an approach of MPPT based on a voltage control approach of power converter with the use of the Adaptive Fuzzy logic controller (Adaptive FLC). The input voltage reference is adaptively perturbed with variable steps until the maximum power is reached. A state-space model is derived through averaging method, with the control input being the modulation depth of the proposed Inverter. The proposed control scheme achieved stable condition in the control region of the PV panel and eliminated the steady state oscillations when there is sudden change of irradiance in the maximum power operating point. Furthermore, the PV system became more efficient, as proven by sudden change in radiation conditions for 0.2 seconds, where energy can be saved approximately $95 \%$. As the max error percentage (Kindly refer to Fig.29)

Keywords - Electrical engineering; Solar Energy; Grid Connected ; averaging model; combination IP; boost converter; photovoltaic; irradiance. 


\section{INTRODUCTION}

Solar power generation is becoming increasingly important as a renewable energy source due to advantages of clean energy, requiring less maintenance and so forth. The output power of photovoltaic (PV) arrays always changes according to the weather conditions, i.e., irradiance and atmospheric temperature. In many cases, the PV system has a disadvantage in the solar radiance conversion into electrical energy. University of Tokyo has tested more than 71 Japanese PV systems, and all showed losses of up to 25\% (Fangrui Liu. 2008). Therefore, efforts to improve energy efficiency are conducted by using maximum power point tracking (MPPT) control [1], so that the maximum power extracted from the PV array in real time becomes indispensable in solar power systems. There are many techniques to get the MPP such as the P\&O (Perturb \&Observation), IC (Incremental Conductance) \& FLC (Fuzzy Logic Control).[2] [3]

In recent years, a large number of techniques have been proposed for tracking the maximum power point (MPP). one of them is the PS (Particle Swarm) [4] .Fractional open-circuit voltage and short-circuit current strategies provide a simple and effective way to acquire the maximum power (Fangrui Liu. 2008). Hill climbing or perturb and observe (P\&O) methods are widely applied in the MPPT controllers due to their simplicity and easy implementation.

Boost converter, also known as the step-up converter, is considered the most beneficial in the solar cell application because of its simplicity, low cost, and high efficiency. In theory, the steady state oscillations should be eliminated since the derivative of the power with respect to the voltage vanishes at MPP. However, the value of the slope of the PV array power versus voltage curve seldom is always null due to the resolution of digital implementation. The neural network and the Non iterative are also considered of the MPP techniques that helps in reaching the MPP [5] [6].

This research proposes the improvement of the tracking accuracy and dynamic performance under sudden change of irradiance conditions.

\section{PHOTOVOLTAIC/ SOLAR CELLS SYSTEM MODEL}

There are two types of solar cells model used for different purposes; firstly, a static model without using a transfer functions of low pass filter (LPF), and secondly, the state-space model of the PV-boost system is obtained based on the solar cells model integrated with LPF as a basis to make the solar power plant simulation such as a real condition, which is expected to design a new MPPT algorithm approach [7] [8]. The two modeling schemes are presented, respectively, in the following sections (Li, Xiao, Yaoyu Li, and John E, 2012). 


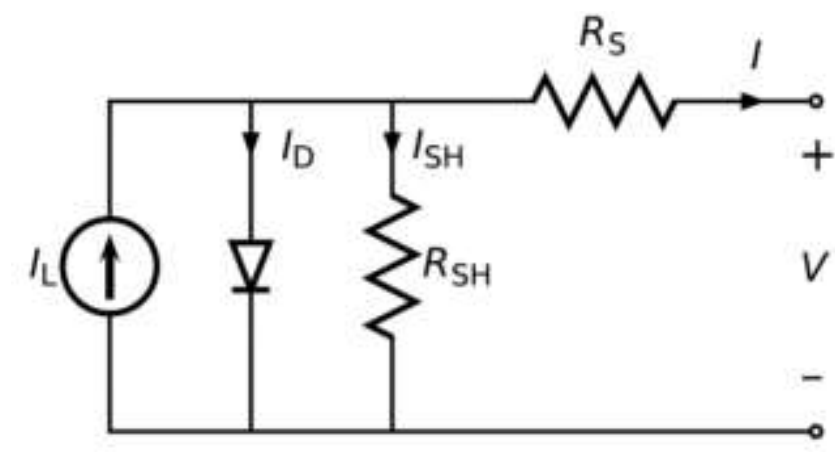

Fig.1 (Photovoltaic Equivalent Circuit)

\section{CHARACTERISTICS OF SOLAR CELLS}

Exponential equation used to make a solar cell model is derived from the laws of physics for the p-n junction, which is generally accepted as presentation of cell characteristics. For modeling of PV statics, the equivalent circuit of PV system in Fig.1 is adopted. The characteristic of the I-V curve can be modeled.

$$
I=I p h-I s\left(\exp \left(\frac{q(V+I R s)}{N K T}\right)-1\right)-\frac{(V+I R s)}{R s h}
$$

where, V and I are the voltage and current, respectively. Iph is the short-circuit current and Is is the reverse saturation (or leakage) current of the diode. $\mathrm{N}$ is the ideality factor of the diode, $\mathrm{T}$ is the thermal voltage of the solar cell arrays in $\operatorname{Kelvin}(\mathrm{K}) . \mathrm{q}$ is the electron charge with the value of $1.60217646 \times 10 \exp -19 \mathrm{C}, \mathrm{K}=1.3806503 \times 10 \mathrm{exp}-23, \mathrm{~J} / \mathrm{K}$ is the Boltzmann constant. Rs and Rsh are the equivalent series and shunt resistance of the solar cell array, respectively. The output voltage and current of the solar cells are strongly influenced by environmental conditions, i.e. solar radiation and cell temperature. From Equation (1), Iph is connected with solar radiation, $\mathrm{K} 1$ is the temperature coefficient of short circuit current, Isc is the short-circuit current at a temperature of $25^{\circ} \mathrm{C}, \mathrm{T}$ is the temperature of the solar cell, and $\lambda$ is the solar radiation in $\mathrm{kW} / \mathrm{m}^{2}$.

$$
I p h=[I s c+K 1(T-298)] \frac{\lambda}{100}
$$

Based on Equation (2), it can be seen that at the time of constant temperature, the current generated by photon is directly proportional to the solar radiation. Effect of the solar radiation changes in the PV characteristic curve is shown in Figure 1. Isc is the short circuit current, which means the voltage is zero or the circuit voltage opens at the time, so no current flows [9].

At the time of the current value being zero, it means that the solar radiation of the sun is $400 \mathrm{~W} / \mathrm{m}^{2} ; 0.7$ sun with $1000 \mathrm{~W} / \mathrm{m}^{2} ; 1.5$ sun with $600 \mathrm{~W} / \mathrm{m}^{2} 2.5$ sun with $800 \mathrm{~W} / \mathrm{m}^{2}$, and so forth. If the solar radiation onto photovoltaic cells diminishes, Isc and Voc, change will not be 
significant as in Isc Fig. 2 shows the $\mathrm{P}-\mathrm{V} \& \mathrm{I}-\mathrm{V}$ curves characteristics at temperature of $25^{\circ} \mathrm{C}$ under different irradiance rates [10] [11]. The generated current is shown increasing with the irradiance level.

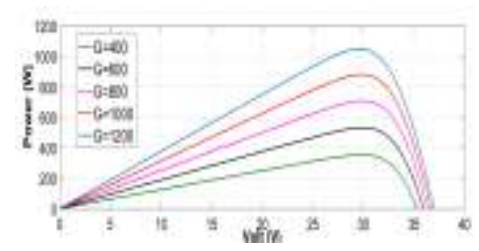

(a)

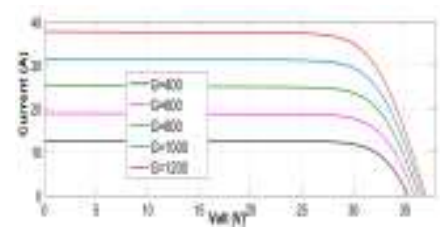

(b)

Fig.2 (a) P-V , (b) I-V curves at $25^{\circ} \mathrm{C}$ characteristics of solar cell under different irradiance

Also in this research the case study of $($ Temp. $=40 \&$ Irradiance $=1000)$ will be examined (Simulated Power signal Vs. Reference Power Signal).

\section{PROPOSED DESIGN OF A NEW APPROACH}

\subsection{FUZZY LOGIC CONTROLLER}

Fuzzy logic (FL) has been available as a control methodology for over four decades in various applications to engineering control systems. Theory of fuzzy sets was introduced by Lotfi A. Zadeh, Professor for computer science at the University of California in Berkeley in 1965 [12] and the industrial application of the first fuzzy controller was initiated by E. H. 
Mamdani in 1974 [13]. Fuzzy systems have obtained a major role in engineering systems and consumer products since then. Fuzzy Logic is a multi-valued logic that allows intermediate values to be defined between conventional evaluations like true/false, yes/no, high/low, etc. Fuzzy logic is a powerful problem solving methodology that provides remarkable simple way to draw definite conclusions from vague, ambiguous or imprecise information [14]. The fuzzy system is a knowledge-based system which utilizes fuzzy if-then rules and fuzzy logic in order to obtain the output of the system.

There are many advantages of using Fuzzy controllers. Firstly, a Fuzzy Logic Controller gives much better output in comparison to the conventional PID controller. The response of FLC system is stable and can be easily varied according to the changing demand for the input. Secondly, the effects of the tuning parameters are jointly analyzed and easy to monitor for varying outputs of PV with changing temperature and irradiance. Thirdly, FLC can be easily tuned according to the desired output by changing the design parameters of membership functions responsible for system performance[15].

FLC implementation in the present work is used to adjust the converter duty cycle by varying the gate voltage according to the changing values of the panel voltage and set point. Practically, panel sensors are incorporated at the end of PV subsystem to measure the online variations in temperature and irradiance. Simulink model designed using FLC is given in Figure 3.

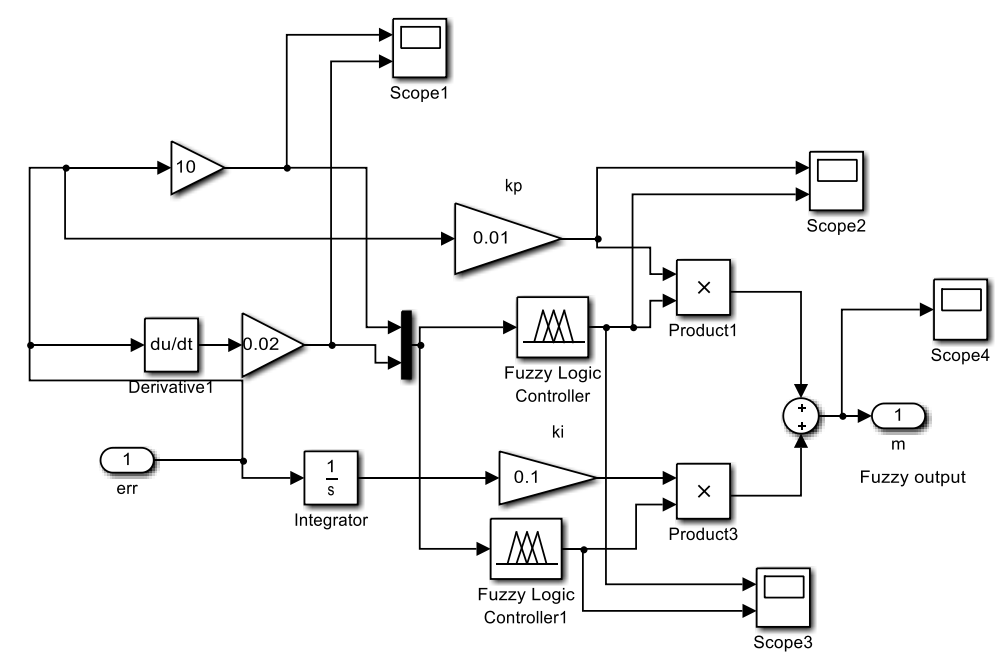

Fig 3 Fuzzy Logic Controller correcting Converter output

The input variables in a fuzzy control system are mapped into sets of membership functions termed "fuzzy sets". The process, of converting a crisp input value to a fuzzy value, is called 
"fuzzification". The "mappings" of input variables into membership functions and truth values help the controller to make decisions for what action is to be taken based on a set of "rules".

The developed FLC uses two inputs with universe of discourse for error input taken $[-1,+1]$ and change in error chosen to be $[-1,+1]$ for the panel voltage. The range of the input variables can be changed according to the changing demand for the varying input. The universe of discourse for the output duty cycle of converter is chosen to be as $[0,1]$. The controller designed is described by two inputs assigned with seven membership functions namely, NB negative big, NM negative medium, NS negative small, Z zero, PS positive small ,PM positive medium and PB positive big.

The controller makes decisions for what action is to be taken based on a set of "rules" implementing the expert knowledge in a form of IF-THEN rule structure. The system was tested for various subsets of error and change in error with changing crossover points. However, Triangle membership functions proved smooth and non-zero at all points with 0.5 crossovers providing less over/under shoot with faster Rise time.

The fuzzy logic developed model can be derived from a rule matrix that consists of 49 rules given in Table 1.

TABLE 1. FUZZY MEMBERSHIP FUNCTIONS

\begin{tabular}{ccllllll}
\hline & & $\mathrm{NM}$ & $\mathrm{NS}$ & $\mathrm{Z}$ & $\mathrm{PS}$ & $\mathrm{PM}$ & $\mathrm{PB}$ \\
\hline $\mathrm{NB}$ & & $\mathrm{VB}$ & $\mathrm{VB}$ & $\mathrm{VB}$ & $\mathrm{VB}$ & $\mathrm{VB}$ & $\mathrm{VB}$ \\
& $\mathrm{VB}$ & & & & & & \\
\hline $\mathrm{NM}$ & $\mathrm{MB}$ & $\mathrm{MB}$ & $\mathrm{MB}$ & $\mathrm{MB}$ & $\mathrm{B}$ & $\mathrm{MB}$ & $\mathrm{VB}$ \\
\hline $\mathrm{NS}$ & $\mathrm{B}$ & $\mathrm{B}$ & $\mathrm{B}$ & $\mathrm{B}$ & $\mathrm{MB}$ & $\mathrm{B}$ & $\mathrm{VB}$ \\
\hline $\mathrm{Z}$ & $\mathrm{Z}$ & $\mathrm{Z}$ & $\mathrm{Z}$ & $\mathrm{MS}$ & $\mathrm{S}$ & $\mathrm{S}$ & $\mathrm{S}$ \\
\hline $\mathrm{PS}$ & $\mathrm{B}$ & $\mathrm{B}$ & $\mathrm{B}$ & $\mathrm{B}$ & $\mathrm{MB}$ & $\mathrm{B}$ & $\mathrm{VB}$ \\
\hline $\mathrm{PM}$ & $\mathrm{MB}$ & $\mathrm{MB}$ & $\mathrm{MB}$ & $\mathrm{MB}$ & $\mathrm{B}$ & $\mathrm{MB}$ & $\mathrm{VB}$ \\
\hline $\mathrm{PB}$ & $\mathrm{VB}$ & $\mathrm{VB}$ & $\mathrm{VB}$ & $\mathrm{VB}$ & $\mathrm{VB}$ & $\mathrm{VB}$ & $\mathrm{VB}$ \\
\hline
\end{tabular}




\section{Hybrid Neuro System}

\subsection{Introduction}

A hybrid intelligent system is one that combines at least two intelligent technologies. For example, combining a neural network with a fuzzy system results in a hybrid neuro-fuzzy system.

Fuzzy logic and neural networks are natural complementary tools in building intelligent systems. While neural networks are low-level computational structures that perform well when dealing with raw data, fuzzy logic deals with reasoning on a higher level, using linguistic information acquired from domain experts.

However, fuzzy systems lack the ability to learn and cannot adjust themselves to a new environment.

On the other hand, although neural networks can learn, they are opaque to the user. Integrated neuro-fuzzy systems can combine the parallel computation and learning abilities of neural networks with the human-like knowledge representation and explanation abilities of fuzzy systems.

As a result, neural networks become more transparent, while fuzzy systems become capable of learning.

A neuro-fuzzy system is a neural network which is functionally equivalent to a fuzzy inference model.

Neuro-Fuzzy System can be trained to develop IF-THEN fuzzy rules and determine membership functions for input and output variables of the system.

The structure of a neuro-fuzzy system is similar to a multi-layer neural network. In general, a neuro-fuzzy system has:

- Input and output layers,

-Three hidden layers that represent membership functions and fuzzy rules.

\subsection{ANFIS}

Since a wide class of fuzzy controllers can be transformed into equivalent adaptive networks, ANFIS can be used for building intelligent controllers that is, controllers that can reason with simple fuzzy inference and that are able to learn from experience in the ANN style

\subsubsection{ANFIS construction (6 layers)}




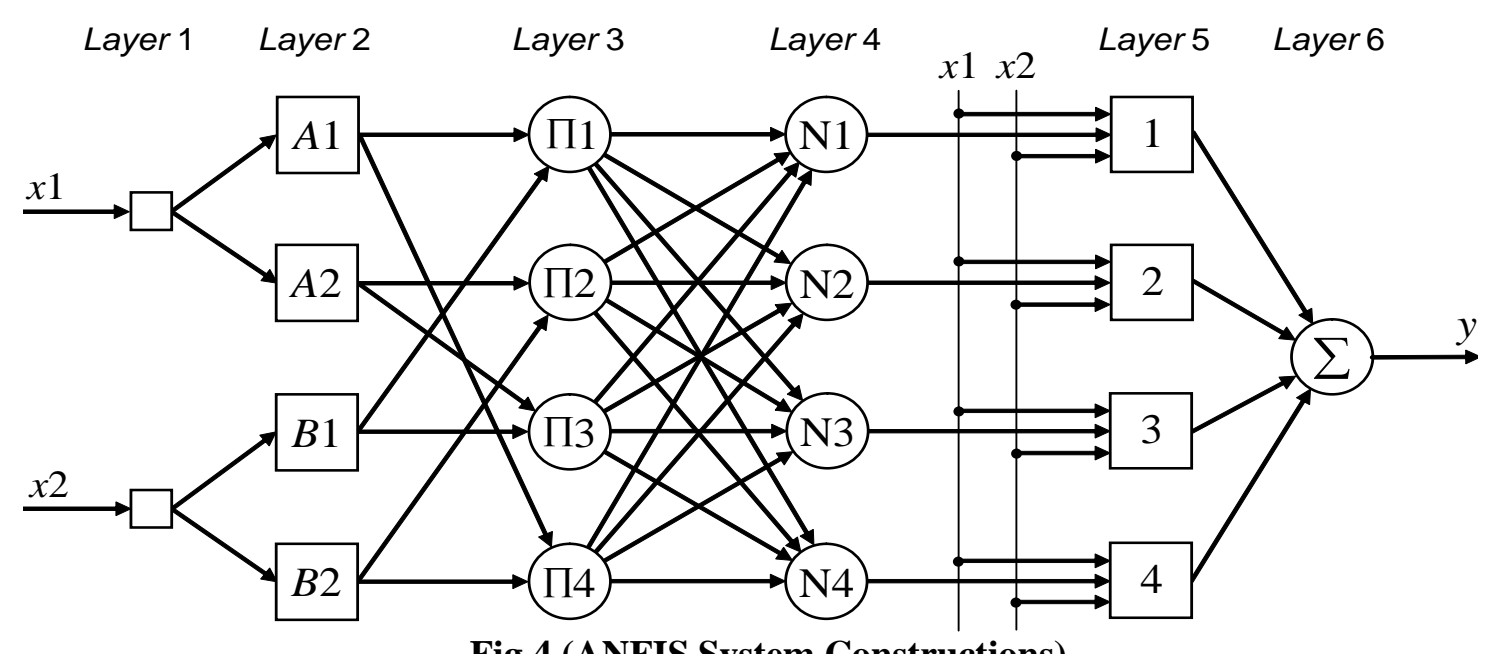

Fig.4 (ANFIS System Constructions)

Layer 1 is the input layer. Neurons in this layer simply pass external signals to Layer 2.

Layer 2 is the fuzzification layer. Neurons in this layer perform fuzzification. (Triangular membership function is used in this example)

\section{MEMBERSHIP FUNCTIONS}

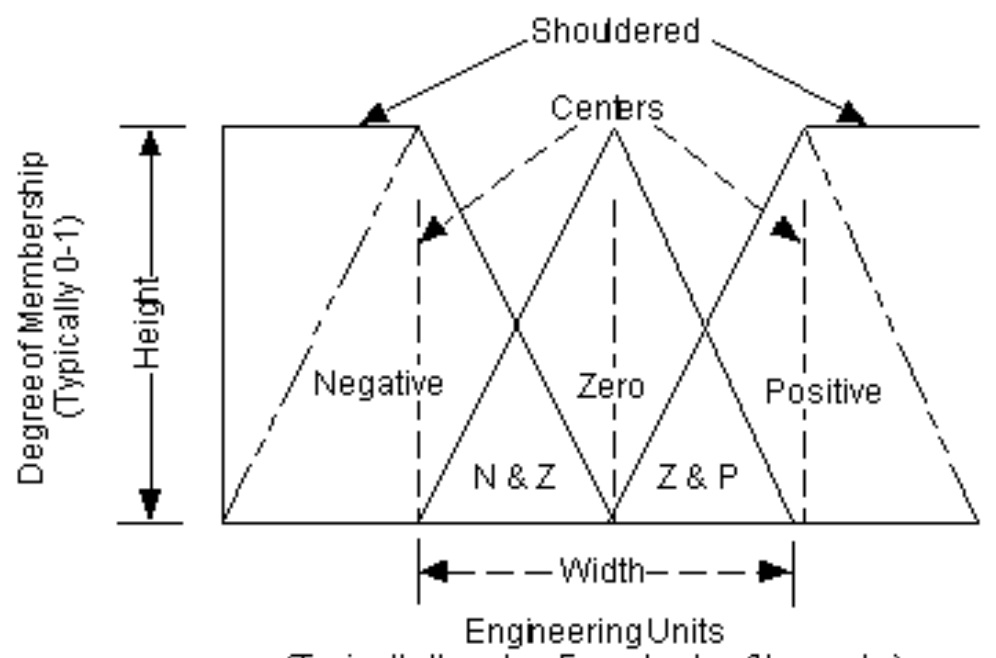

(Typically lbs, deg F, or degim, ft'sec, etc.)

(a) 
ERROR MEMBERSHIP FUNCTION

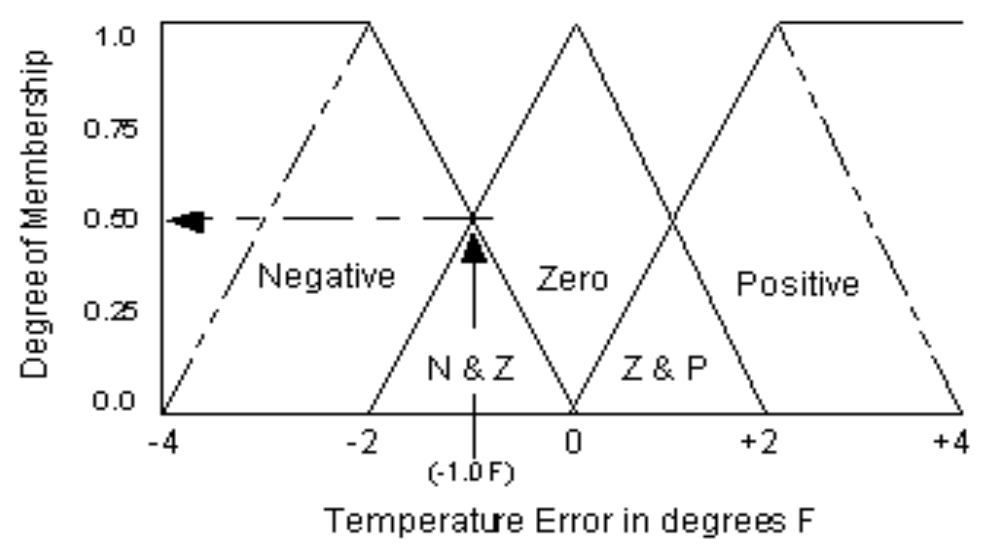

(b)

Fig.5 (a \& b Triangular membership function)

Layer 3 is the rule layer. Each neuron in this layer corresponds to a single Sugeno-type fuzzy rule. A rule neuron receives inputs from the respective fuzzification neurons and calculates the firing strength of the rule it represents.

In an ANFIS, the conjunction of the rule antecedents is evaluated by the operator product.

Layer 4 is the normalization layer. Each neuron in this layer receives inputs from all neurons in the rule layer, and calculates the normalized firing strength of a given rule.

Layer 5 is the defuzzification layer. Each neuron in this layer is connected to the respective normalization neuron, and also receives initial inputs, x1 and x2. A defuzzification neuron calculates the weighted consequent value of a given rule.

Layer 6 is represented by a single summation neuron. This neuron calculates the sum of outputs of all defuzzification neurons and produces the overall ANFIS output (y)

\subsubsection{Function approximation using the ANFIS model}

In this part, an ANFIS is used to follow a trajectory of the non-linear function of the relation between both (Two inputs "Tem \& Irradiance "and One output "Pmax" )

First, we choose an appropriate architecture for the ANFIS. An ANFIS must have two inputs (Temp. and Irradiance) and one output (Pmax).

Thus, in our example, the ANFIS is defined by four rules, and has the structure shown below in Fig.4. The following table represents the exercise done to get the relation between Temp. , Irrad. \& Pmax.

\subsubsection{Different Readings for the Pmax. (Using Different Temp. \& Different} Irradiances) 
The main component parameters of boost converter circuit and PI controller implemented in the Matlab Simulink are given in Table 2

TABLE 2. COMPONENT OF BOOST CONVERTER CIRCUIT

\begin{tabular}{lll}
\hline Symbol & Description & Value \\
\hline $\mathrm{L}$ & Inductance & $0.09 \mathrm{H}$ \\
\hline $\mathrm{fs}$ & Frequency & $5 \mathrm{KHz}$ \\
\hline $\mathrm{C}$ & Load Capacitor & $0.5 \mathrm{~F}$ \\
\hline Ncell & No. of cells per Module & 60 \\
\hline
\end{tabular}

Vertical lines are optional in tables. Statements that serve as captions for the entire

table do not need footnote letters. $\mathrm{H}=$ henry, $\mathrm{Hz}=$ hertz , $\Omega=$ ohms , $\mathrm{F}=$ Farad

TABLE 3. COMPONENT OF PI CONTROLLER

\begin{tabular}{lll}
\hline Symbol & Description & Value \\
\hline $\mathrm{Kp}$ & Proportional Factor & 0.001 \\
\hline $\mathrm{Ki}$ & Integral Factor & 0.015 \\
\hline $\mathrm{TABLE}$ 4. COMPONENT OF FLC CONTROLLER & \\
\hline Symbol & Description & Value \\
\hline $\mathrm{Kp}$ & Proportional Factor & 0.015 \\
\hline $\mathrm{Ki}$ & Integral Factor & 0.002 \\
\hline
\end{tabular}

A vital component of the reference solar cell used in this research is the solar cells, manufactured by AREi (Advanced Renewable Energy), model 220W-M6-G Datasheet), whose specification parameters values are given in Table 5

TABLE 5. PARAMETERS OF AREI 220W-M6-G

\begin{tabular}{lll}
\hline Symbol & Description & Value \\
\hline Pmax & Maximum Power & 220.0716 Watt \\
& & $-5 \%+10 \%$ \\
\hline Voc & Open Circuit Voltage & $36.72 \mathrm{~V}$ \\
\hline Isc & Short Circuit Current & $7.85 \mathrm{~A}$ \\
\hline & Temperature Coefficient & of \\
& Voc & -0.3534 \\
& Temperature Coefficient of Isc & 0.05535 \\
\hline Vmp & & $\% /{ }^{\circ} \mathrm{C}$ \\
\hline Imp & Maximum Power Voltage & $29.82 \mathrm{~V}$ \\
\hline $\mathrm{Ns}$ & Maximum Power Current & $7.38 \mathrm{~V}$ \\
\hline
\end{tabular}


TABLE 6. Max. Power for different Temp. \& Irradiations

\begin{tabular}{|c|c|c|c|c|}
\hline Ser. & Temp. & Irradiation & $\begin{aligned} P(\max ) & \text { for } \\
\text { Series PVs } & \end{aligned}$ & 4 \\
\hline 1 & 10 & 0 & 0.0000 & 0.2 \\
\hline 2 & 10 & 10 & 6.1943 & 0.2 \\
\hline 3 & 10 & 20 & 12.3898 & 0.2 \\
\hline 4 & 10 & 30 & 18.5852 & 0.2 \\
\hline 5 & 10 & 40 & 24.7805 & 0.2 \\
\hline 6 & 10 & 50 & 30.9757 & 0.2 \\
\hline 7 & 10 & 60 & 37.1708 & 0.2 \\
\hline 8 & 10 & 70 & 43.3658 & 0.2 \\
\hline 9 & 10 & 80 & 49.5606 & 0.2 \\
\hline 10 & 10 & 90 & 55.7554 & 0.2 \\
\hline 11 & 15 & 100 & 62.1222 & 0.2 \\
\hline 12 & 15 & 110 & 68.3341 & 0.2 \\
\hline 13 & 15 & 120 & 74.5458 & 0.2 \\
\hline 14 & 15 & 130 & 80.7574 & 0.2 \\
\hline 15 & 15 & 140 & 86.9689 & 0.2 \\
\hline 16 & 15 & 150 & 93.1803 & 0.2 \\
\hline 17 & 15 & 160 & 99.3915 & 0.2 \\
\hline 18 & 15 & 170 & 105.6027 & 0.2 \\
\hline 19 & 15 & 180 & 111.8137 & 0.2 \\
\hline 20 & 15 & 190 & 118.0246 & 0.2 \\
\hline 21 & 20 & 300 & 186.8540 & 0.2 \\
\hline 22 & 20 & 320 & 199.3075 & 0.2 \\
\hline 23 & 20 & 360 & 224.2131 & 0.2 \\
\hline 24 & 20 & 380 & 236.6651 & 0.2 \\
\hline 25 & 20 & 400 & 249.1167 & 0.2 \\
\hline 26 & 20 & 420 & 261.5678 & 0.2 \\
\hline 27 & 20 & 440 & 274.0184 & 0.2 \\
\hline 28 & 20 & 460 & 286.4685 & 0.2 \\
\hline 29 & 20 & 480 & 298.9182 & 0.2 \\
\hline
\end{tabular}




\begin{tabular}{|c|c|c|c|c|}
\hline 30 & 20 & 500 & 311.3673 & 0.2 \\
\hline 31 & 21 & 600 & 373.8125 & 0.2 \\
\hline 32 & 22 & 600 & 374.0188 & 0.2 \\
\hline 33 & 23 & 600 & 374.2249 & 0.2 \\
\hline 34 & 24 & 600 & 374.4306 & 0.2 \\
\hline 35 & 25 & 600 & 374.6360 & 0.2 \\
\hline 36 & 26 & 600 & 374.8411 & 0.2 \\
\hline 37 & 27 & 600 & 375.0457 & 0.2 \\
\hline 38 & 28 & 600 & 375.2499 & 0.2 \\
\hline 39 & 29 & 600 & 375.4536 & 0.2 \\
\hline 40 & 29.5 & 600 & 375.5552 & 0.2 \\
\hline 41 & 30 & 700 & 438.2244 & 0.2 \\
\hline 42 & 31 & 700 & 438.4605 & 0.2 \\
\hline 43 & 31.5 & 700 & 438.5783 & 0.2 \\
\hline 44 & 31.75 & 700 & 438.6371 & 0.2 \\
\hline 45 & 32 & 700 & 438.6959 & 0.2 \\
\hline 46 & 32.5 & 700 & 438.8132 & 0.2 \\
\hline 47 & 32.75 & 700 & 438.8718 & 0.2 \\
\hline 48 & 33 & 700 & 438.9303 & 0.2 \\
\hline 49 & 33.5 & 700 & 439.0472 & 0.2 \\
\hline 50 & 34 & 700 & 439.1638 & 0.2 \\
\hline 51 & 35 & 710 & 445.6688 & 0.2 \\
\hline 52 & 35 & 720 & 451.9414 & 0.2 \\
\hline 53 & 35 & 730 & 458.2137 & 0.2 \\
\hline 54 & 35 & 740 & 464.4860 & 0.2 \\
\hline 55 & 35 & 750 & 470.7581 & 0.2 \\
\hline 56 & 35 & 760 & 477.0300 & 0.2 \\
\hline 57 & 35 & 770 & 483.3018 & 0.2 \\
\hline 58 & 35 & 780 & 489.5734 & 0.2 \\
\hline 59 & 35 & 790 & 495.8449 & 0.2 \\
\hline 60 & 35 & 800 & 502.1163 & 0.2 \\
\hline 61 & 35.5 & 900 & 564.9696 & 0.2 \\
\hline 62 & 36 & 910 & 571.3903 & 0.2 \\
\hline
\end{tabular}




\begin{tabular}{|c|c|c|c|c|}
\hline 63 & 36.5 & 920 & 577.8134 & 0.2 \\
\hline 64 & 37 & 930 & 584.2391 & 0.2 \\
\hline 65 & 37.5 & 940 & 590.6673 & 0.2 \\
\hline 66 & 38 & 950 & 597.0978 & 0.2 \\
\hline 67 & 38 & 960 & 603.3761 & 0.2 \\
\hline 68 & 38 & 970 & 609.6542 & 0.2 \\
\hline 69 & 38 & 980 & 615.9322 & 0.2 \\
\hline 70 & 38 & 990 & 622.2100 & 0.2 \\
\hline 71 & 38.2 & 1000 & 628.5519 & 0.2 \\
\hline 72 & 38.4 & 1010 & 634.8948 & 0.2 \\
\hline 73 & 38.6 & 1020 & 641.2386 & 0.2 \\
\hline 74 & 38.8 & 1030 & 647.5833 & 0.2 \\
\hline 75 & 39 & 1040 & 653.9289 & 0.2 \\
\hline 76 & 39 & 1050 & 660.2086 & 0.2 \\
\hline 77 & 39 & 1060 & 666.4881 & 0.2 \\
\hline 78 & 39 & 1070 & 672.7674 & 0.2 \\
\hline 79 & 39 & 1080 & 679.0466 & 0.2 \\
\hline 80 & 39 & 1090 & 685.3255 & 0.2 \\
\hline 81 & 39 & 1100 & 691.6042 & 0.2 \\
\hline 82 & 39 & 1110 & 697.8827 & 0.2 \\
\hline 83 & 39 & 1120 & 704.1611 & 0.2 \\
\hline 84 & 39 & 1130 & 710.4392 & 0.2 \\
\hline 85 & 39 & 1140 & 716.7171 & 0.2 \\
\hline 86 & 39 & 1150 & 722.9948 & 0.2 \\
\hline 87 & 39 & 1160 & 729.2724 & 0.2 \\
\hline 88 & 39 & 1180 & 741.8268 & 0.2 \\
\hline 89 & 40 & 1200 & 754.7564 & 0.2 \\
\hline 90 & 41 & 1200 & 755.1281 & 0.2 \\
\hline 91 & 42 & 1200 & 755.4951 & 0.2 \\
\hline 92 & 43 & 1200 & 755.8568 & 0.2 \\
\hline 93 & 44 & 1200 & 756.2129 & 0.2 \\
\hline 94 & 45 & 1200 & 756.5626 & 0.2 \\
\hline 95 & 46 & 1200 & 756.9055 & 0.2 \\
\hline
\end{tabular}




\begin{tabular}{lllll}
96 & 47 & 1200 & 757.2409 & 0.2 \\
\hline 97 & 48 & 1200 & 757.5680 & 0.2 \\
\hline 98 & 49 & 1200 & 757.8862 & 0.2 \\
\hline 99 & 50 & 1200 & 758.1945 & 0.2 \\
\hline 100 & 51 & 1200 & 758.4920 & 0.2 \\
\hline
\end{tabular}

\subsubsection{MATLAB Simulation for An ANFIS model with four rules}

Herein below mentioned steps for the MATLAB simulation of the ANFIS model:

1- After saving the desired ANFIS training data in a format of MATLAB data file "Name.dat" , Type on the command window "Anfisedit"

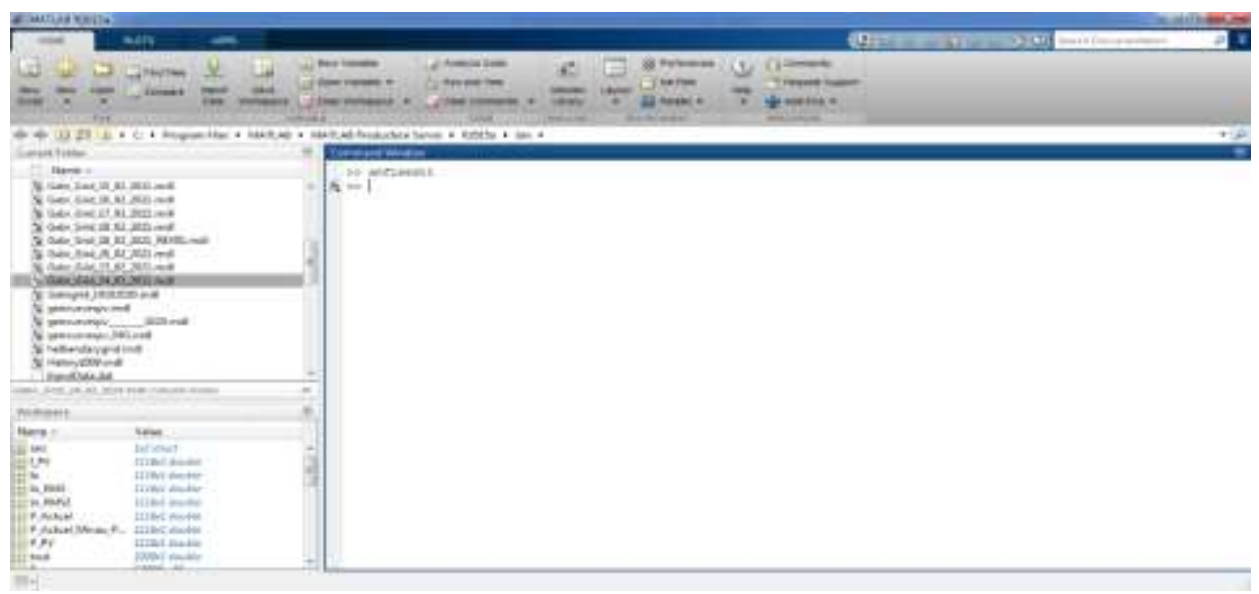

Fig.7 (Anfisedit)

2- It will show the following window, then select Load Data

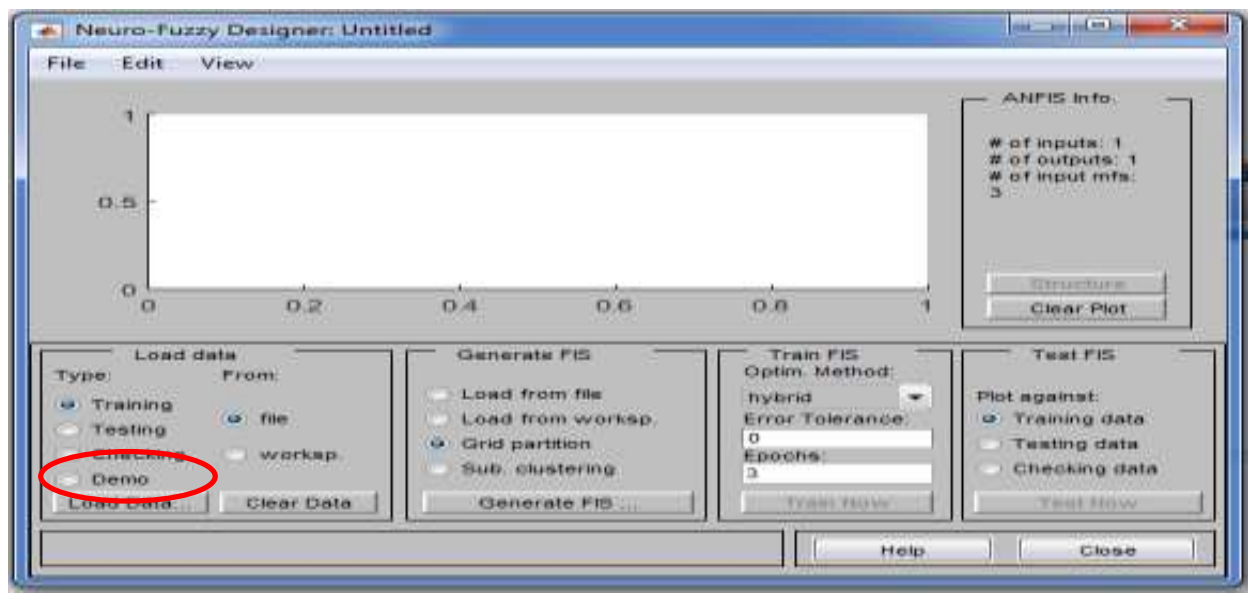

Fig.8 (Anfis data loading) 


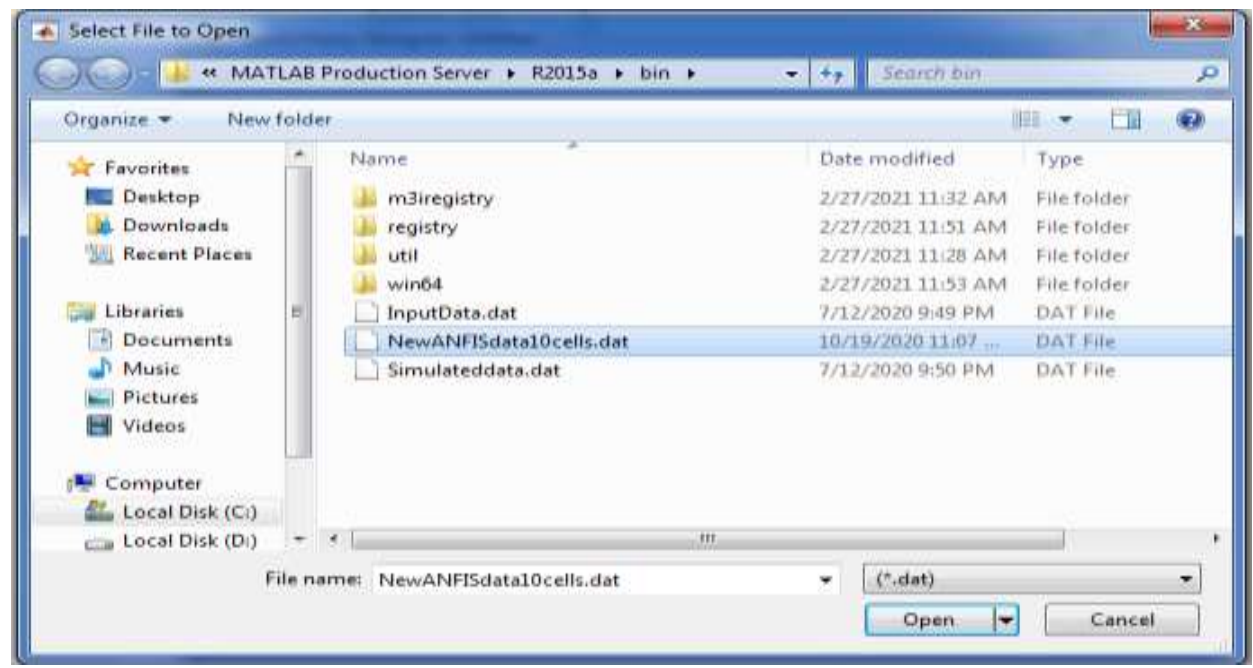

Fig.9 (Anfis data loading-Selecting file)

3- After selecting the data file it will show its content, then generating the FIS file

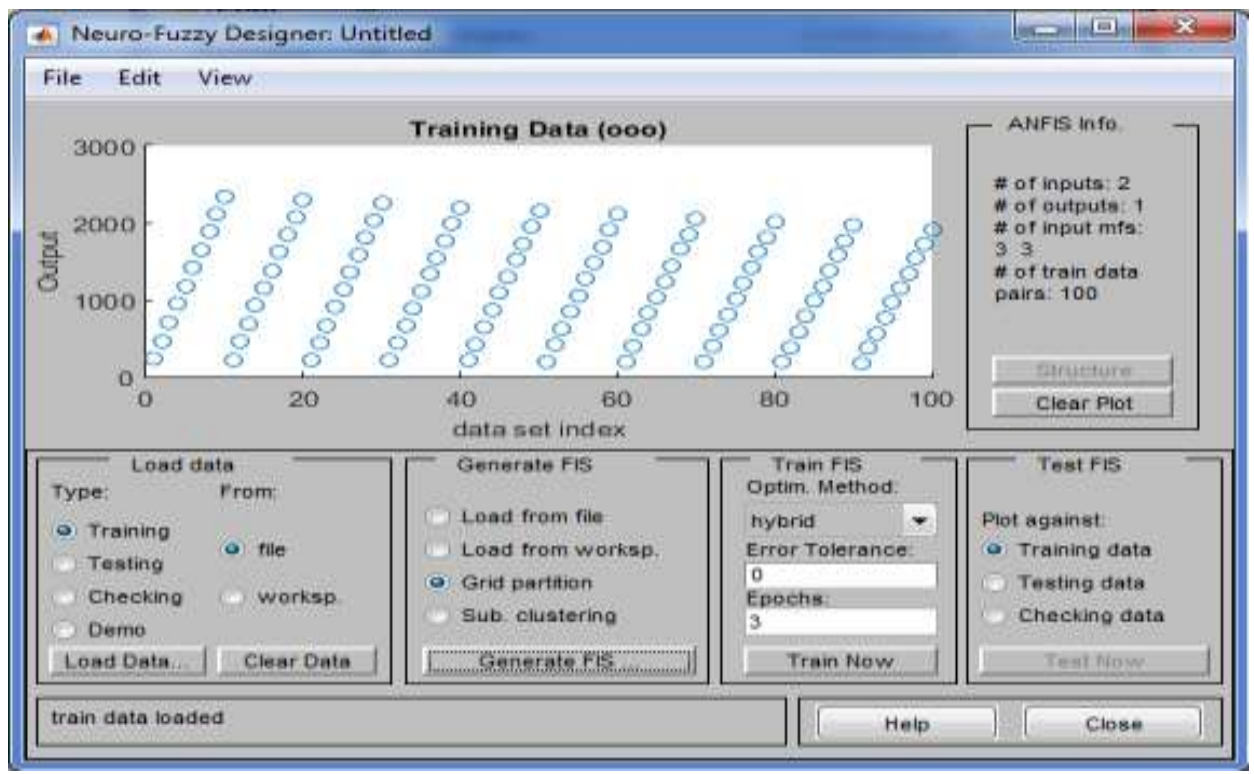

Fig.10 (Anfis FIS Generate)

This figure show the two I/P data which are (Irradiance \& Temp.) to the correspondent PV array and the $\mathrm{O} / \mathrm{P}$ data is the max. Power.

4- Generating the FIS , selecting the Gaussian membership function (gaussmf) and its type is linear 


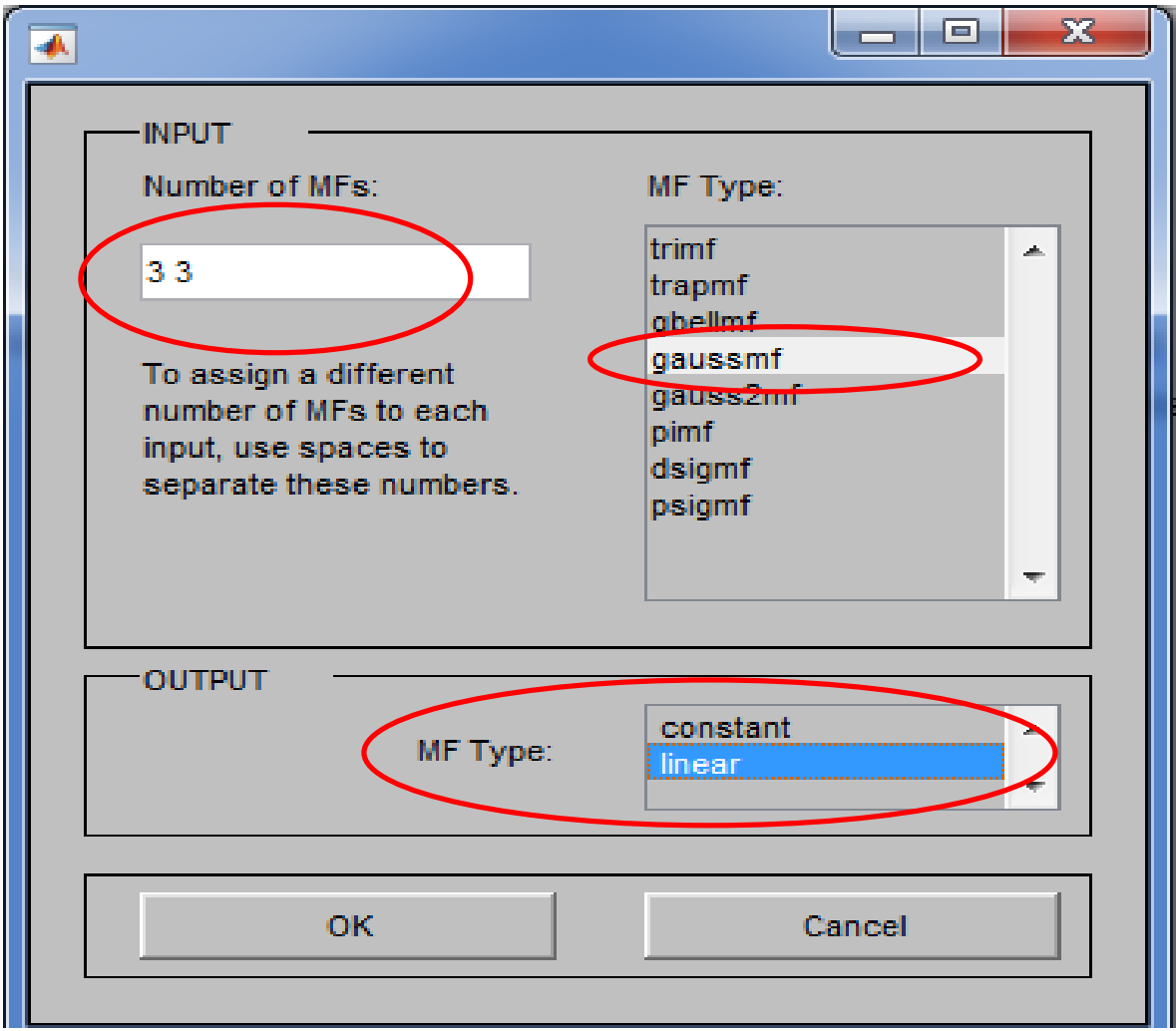

Fig.11 (Anfis membership function)

5- Checking the structure of the ANFIS file as the following :

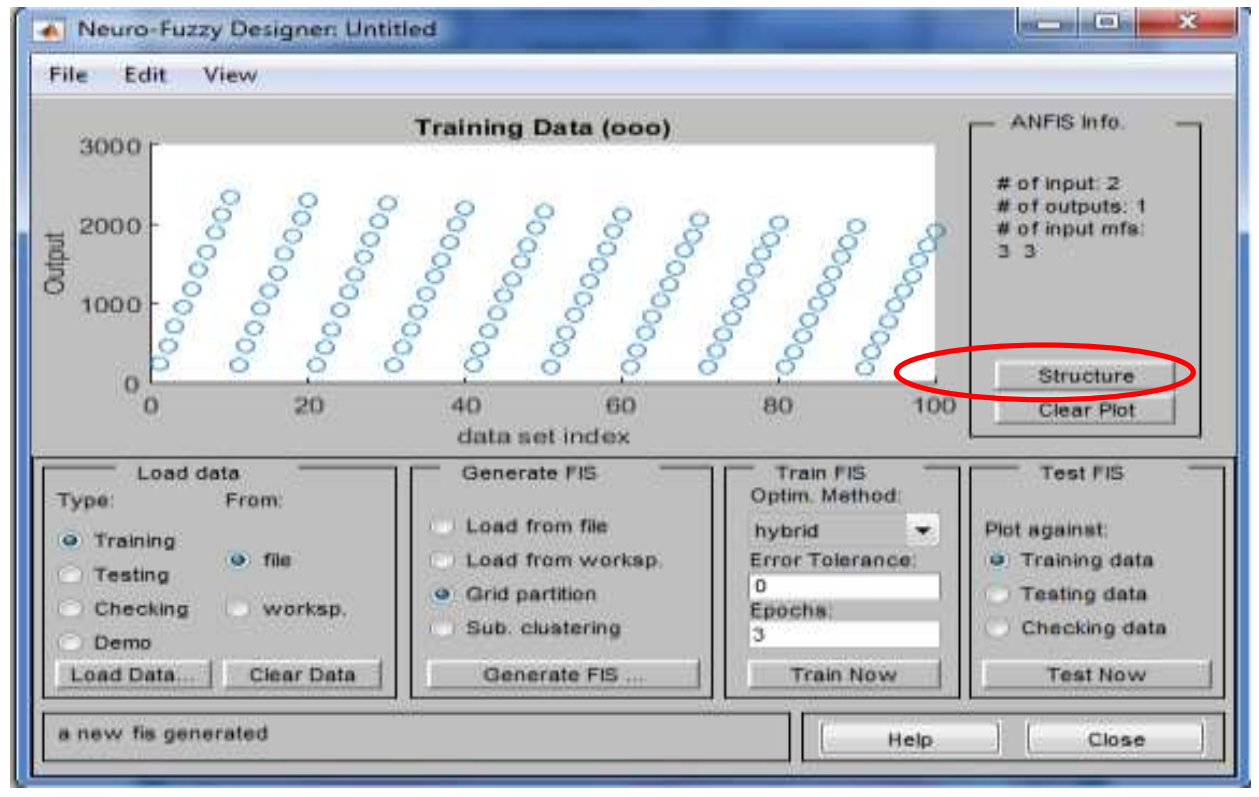

Fig.12 (Anfis structure selection)

3 No. membership function for each I/P and 9 rules . 


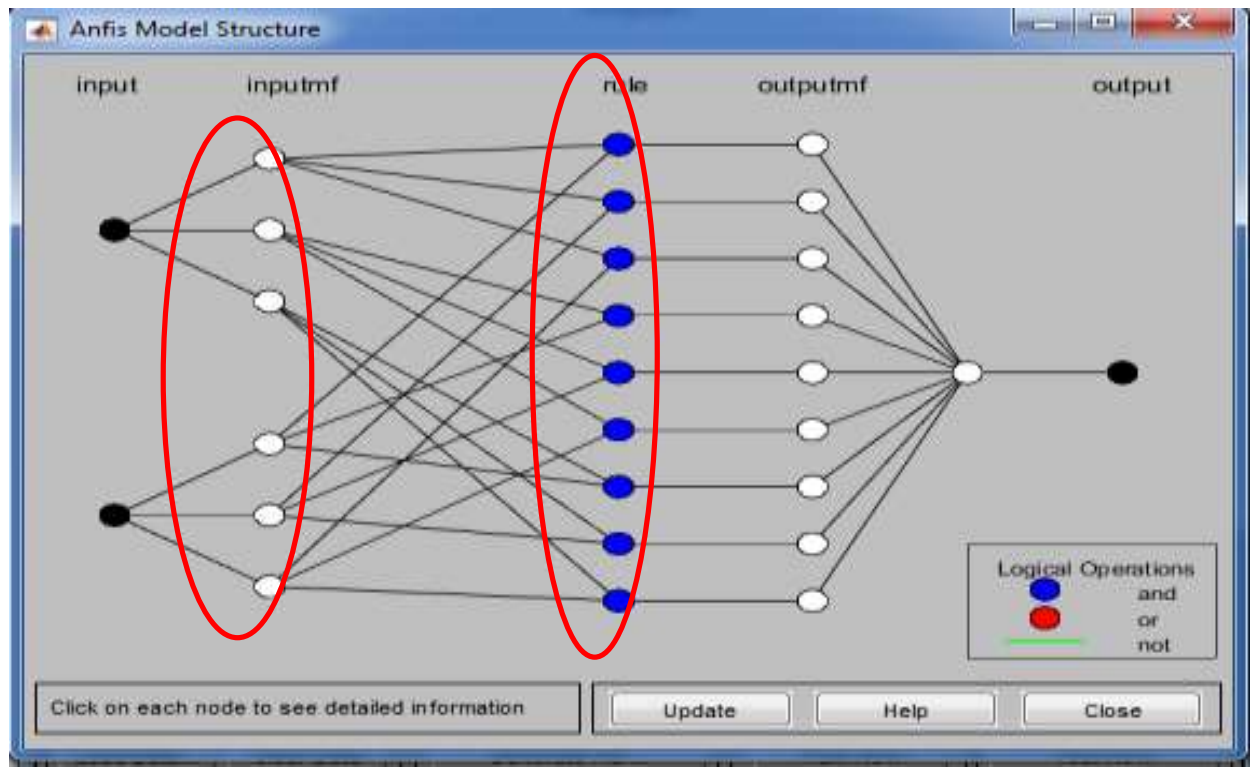

Fig.13 (Anfis structure)

6- Train the ANFIS file now \& check the error :

First, the more number of Epoch , this case number of Epoch is 3 , then pressing test now

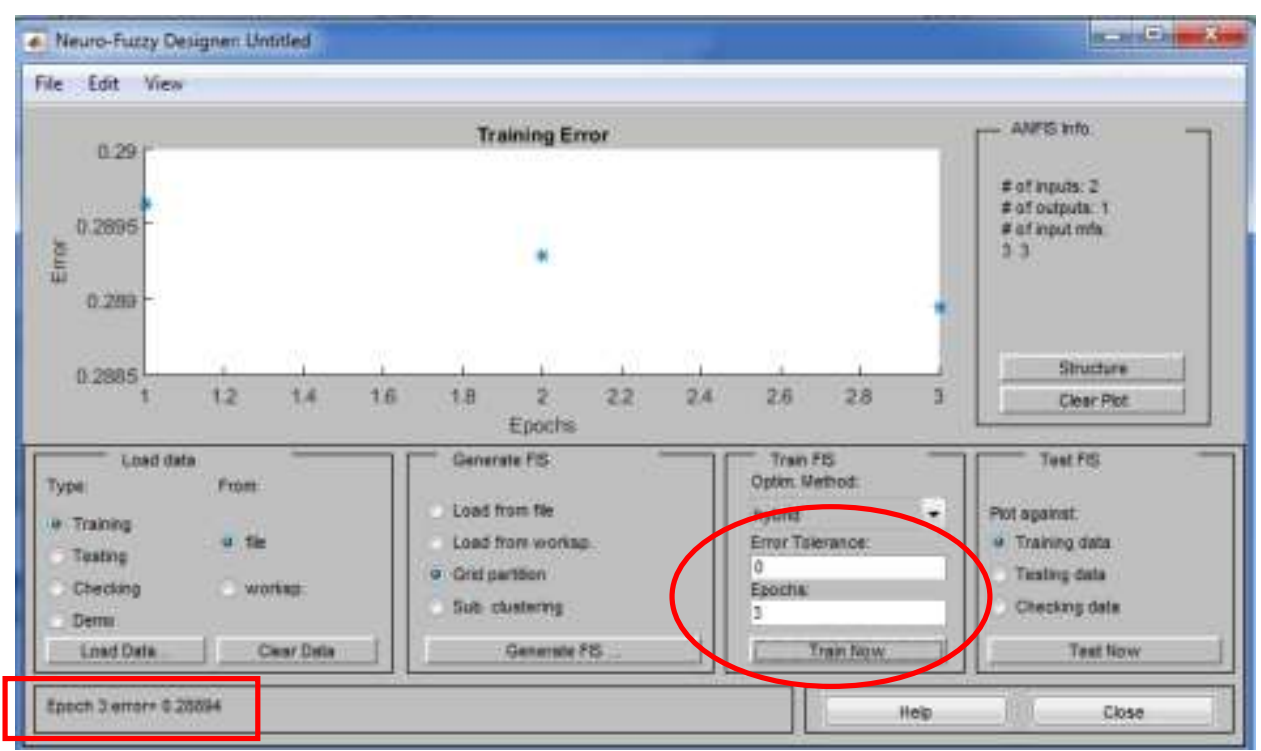

Fig.14 (Anfis training) 


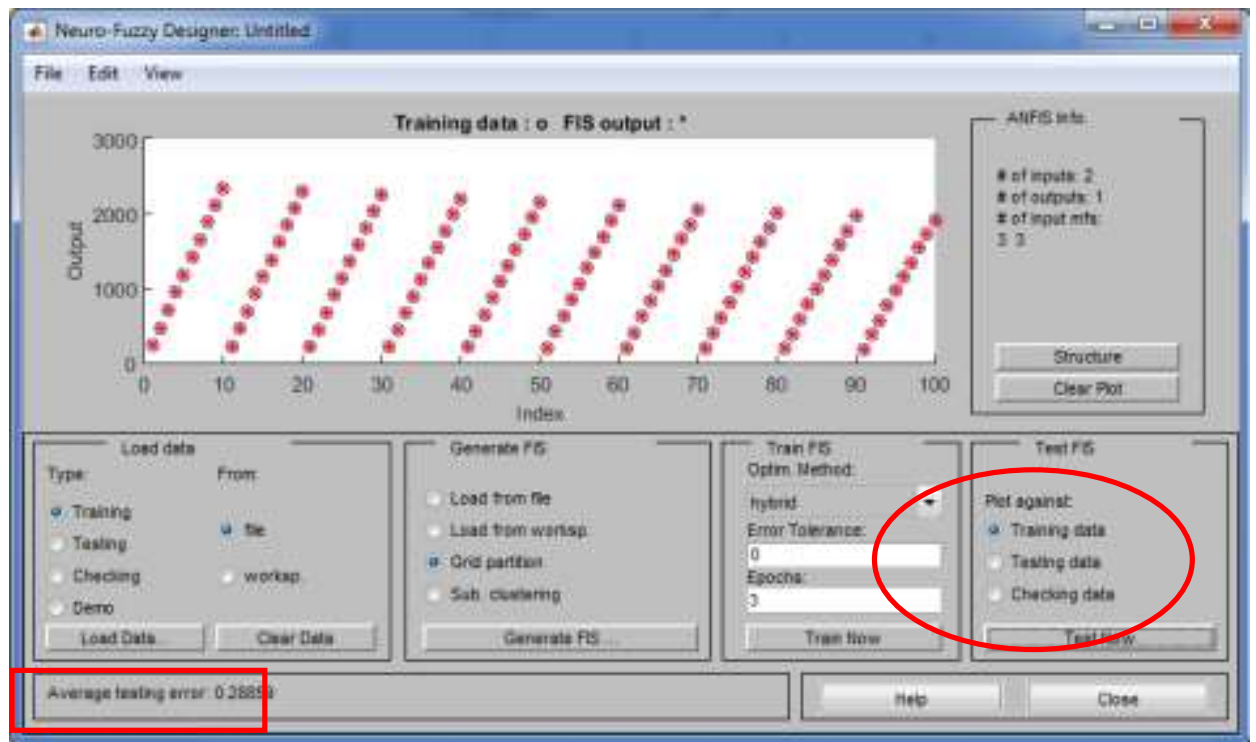

Fig.15 (Anfis testing)

Average error is 0.28859 which is accepted.

7- Save as the FIS file in order to use it in the MATLAB simulation

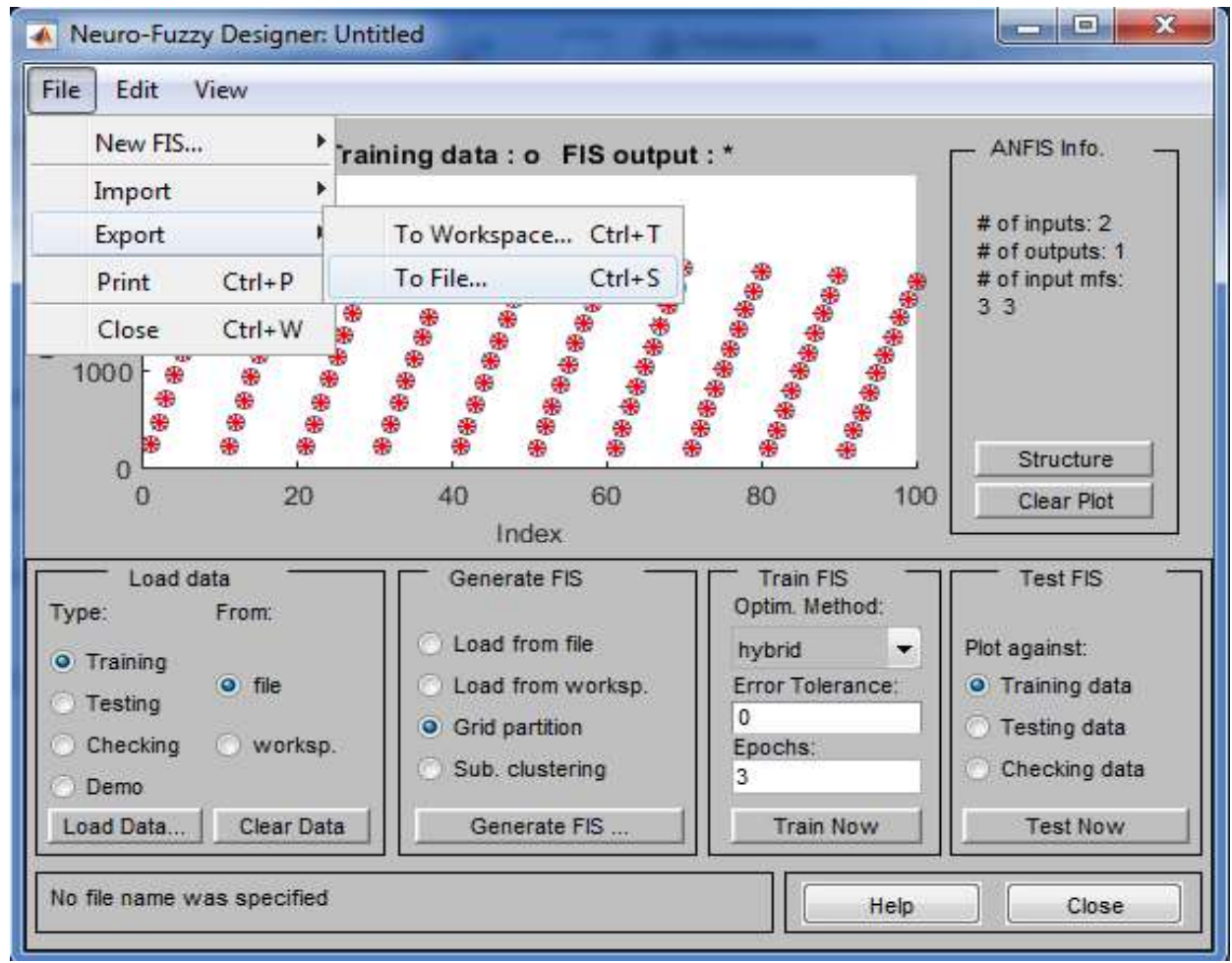

Fig.16 (Anfis after test)

Mohammed F. Gabr et al., IJAEBS (2021), (2), (1), (100-131) 


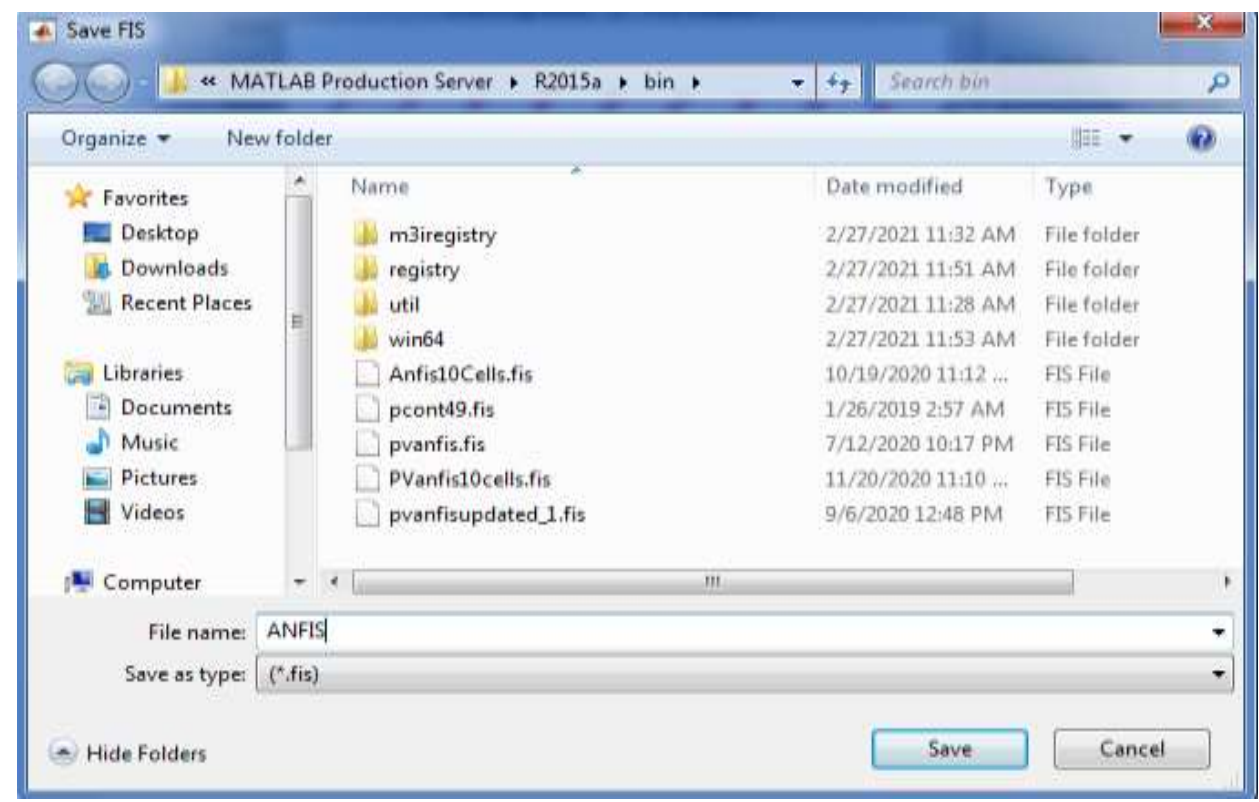

Fig.17 (Anfis save as)

\subsection{Grid Connected System}

\subsubsection{Introduction}

A PV system connected to the grid without batteries is the simplest and most economical solar energy installation available and since it does not require batteries, it is more cost-effective and requires less maintenance and reinvestment than stand-alone systems. It should be noted that a grid-connected solar energy system feeds their solar energy directly back into the grid. If, on a sunny day, the photo-voltaic solar system produces more electricity, this solar energy is instantly reintroduced into the grid based on insolation conditions and actual electricity demand [16][17].

Grid-connected photovoltaic systems are composed of photovoltaic panels connected to the grid via a DC-AC inverter with a maximum power tracker (MPPT) and a permanent controller of the power injected, a bidirectional interface between the AC output circuits of the PV system and the grid, the main electricity grid and the DC and AC loads as well as the control system necessary to ensure the safe operation of the group

To effectively control the power flow in the electrical system, multiple parameters and specific conditions are taken into consideration when connecting PV energy to the grid. The impact of PV modules on power grids cannot be ignored. Grid-connected PV systems can cause problems with the grid's flow control and stability. 
In this simulated example, the design of a photovoltaic grid-connected system using a controller for monitoring the maximum power point of the PV farm (MPPT) of type (Adaptive FLC).

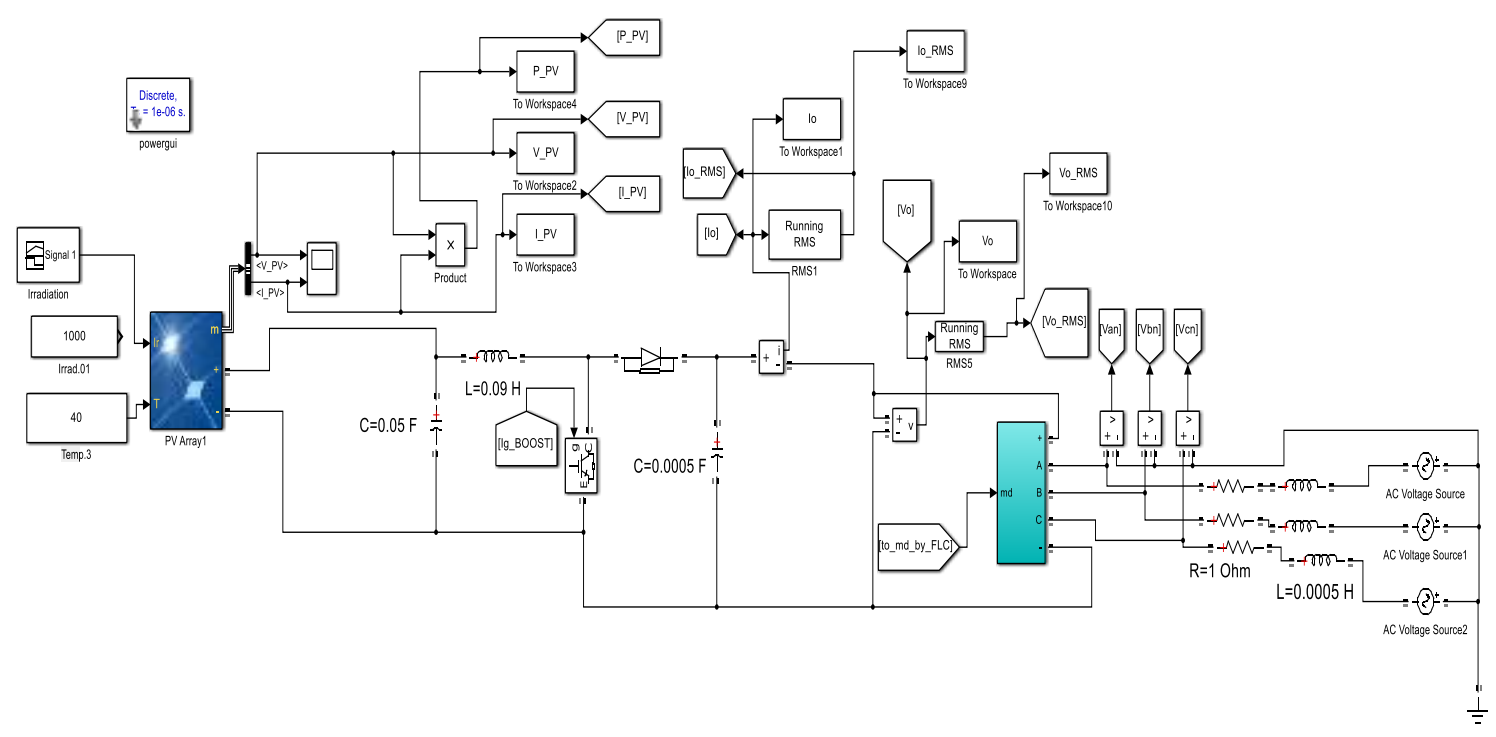

Fig.18 (MATLAB Simulation of Grid Connected system)

Grid Impedance $R=1$ Ohms \& L=0.0005 H

\subsubsection{Methods}

A grid-connected inverter's control system is responsible for managing a distributed generator's power injection into the grid

In such a way that the grid-connected photovoltaic system will operate flexibly, reliably and efficiently, it is necessary to comply with the following instructions, namely the order of the phases for the solar installation and the grid, frequency and voltage adaptation, and the sequence of the phases for the solar installation and the grid [18].

To overcome these constraints, a control strategy for the PV system injected into the grid is implemented. 


\subsubsection{Simulation \& Result.}
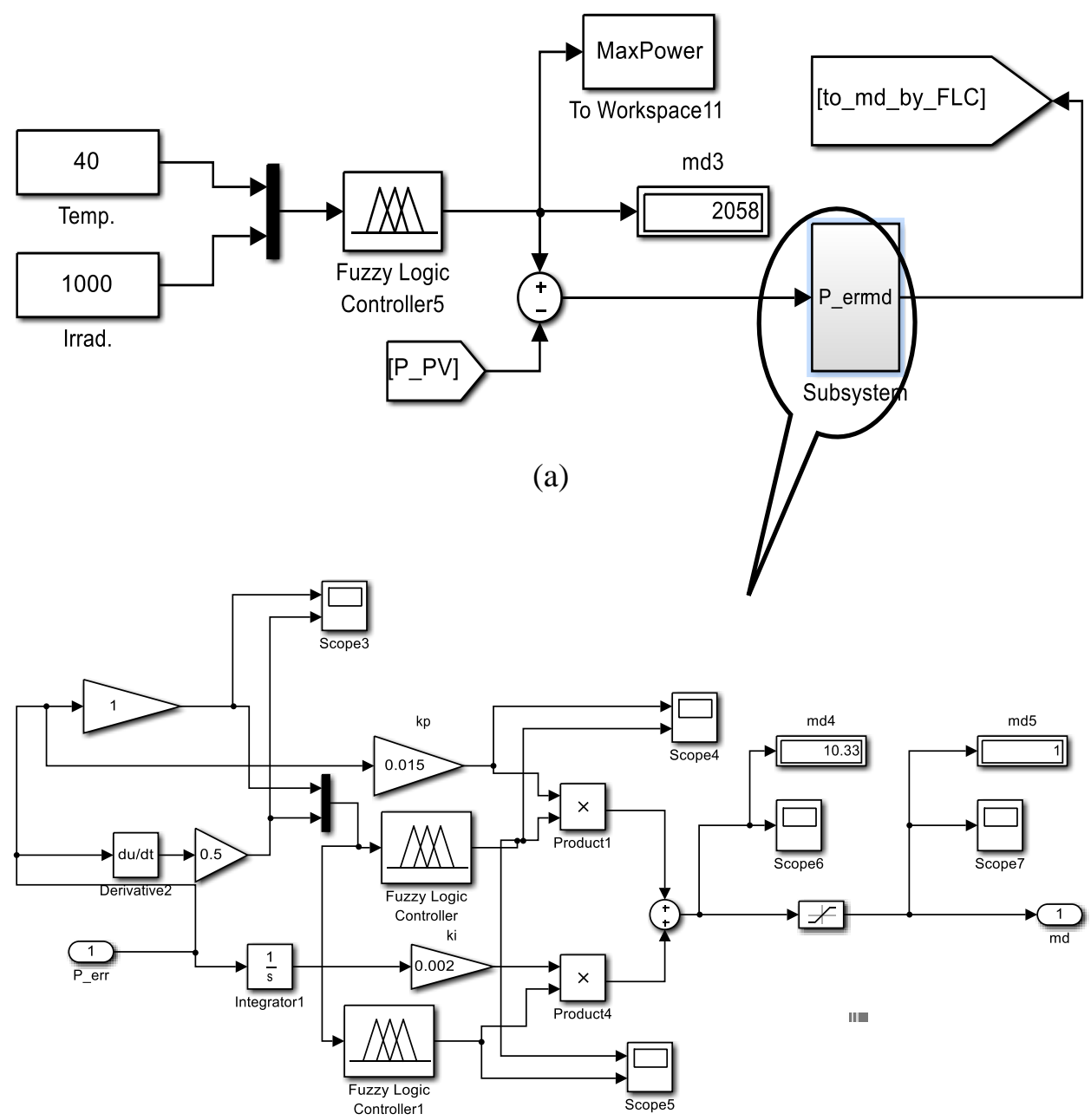

(b)

Fig.19 (a\&b Simulated Adaptive FLC circuit) 


\subsubsection{System Description}

This control is associated to an inverter that allows an adaptation between the PV and the load so that the power generated corresponds to its maximum value and is transferred directly to the grid. The MPPT control is established in this study using the algorithm (Adaptive FLC). This Controller is using the combination between the Artificial \& Fuzzy logic control, as the adaptation of the fuzzy inference system (FIS) is already trained controller to get the Max. Power \& Tracking it.

First, as shown in fig.19 (a) a const. temp. \& irrad. are connected to multiplexer which is connected to the Trained FIS in order to get the reference Pmax. Which is subtracted from the simulated Pmax to get the error.

This error is passes through the control circuit as shown in fig.19 (b)

To get the Inverter's Gate signals (md).

Finally, the followings are the result of the case study (Temp. $40{ }^{\circ} \mathrm{C} \& \operatorname{Irrad} .1000 \mathrm{w} / \mathrm{m}^{2}$ )

\subsection{Case Study (1) : Temp. $40{ }^{\circ} \mathrm{C} \&$ Irrad. $1000 \mathrm{w} / \mathrm{m}^{2}$}

As early stated in the abstract, the ANFIS appear clearly in the fast response of the signal (in transient state) $\approx 0.2$ Sec. to get in the Steady state

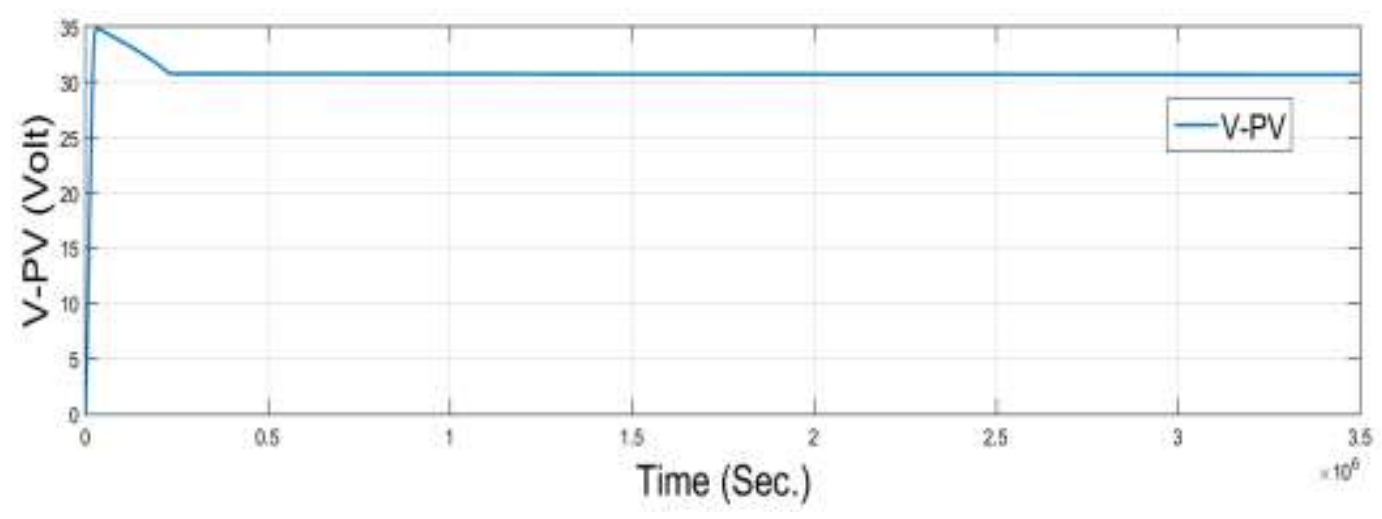

Fig.20: V-PV

$\mathrm{V}-\mathrm{PV}$ is $\approx(32 \mathrm{~V})$ 


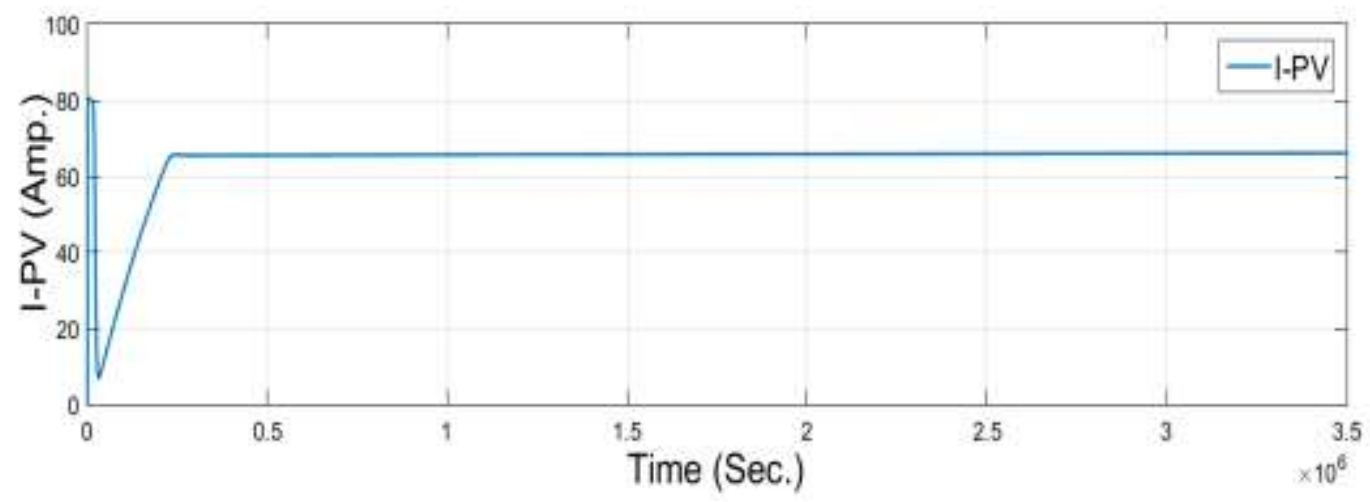

Fig.21: I-PV

$\mathrm{I}-\mathrm{PV}$ is $\approx(66 \mathrm{~A})$

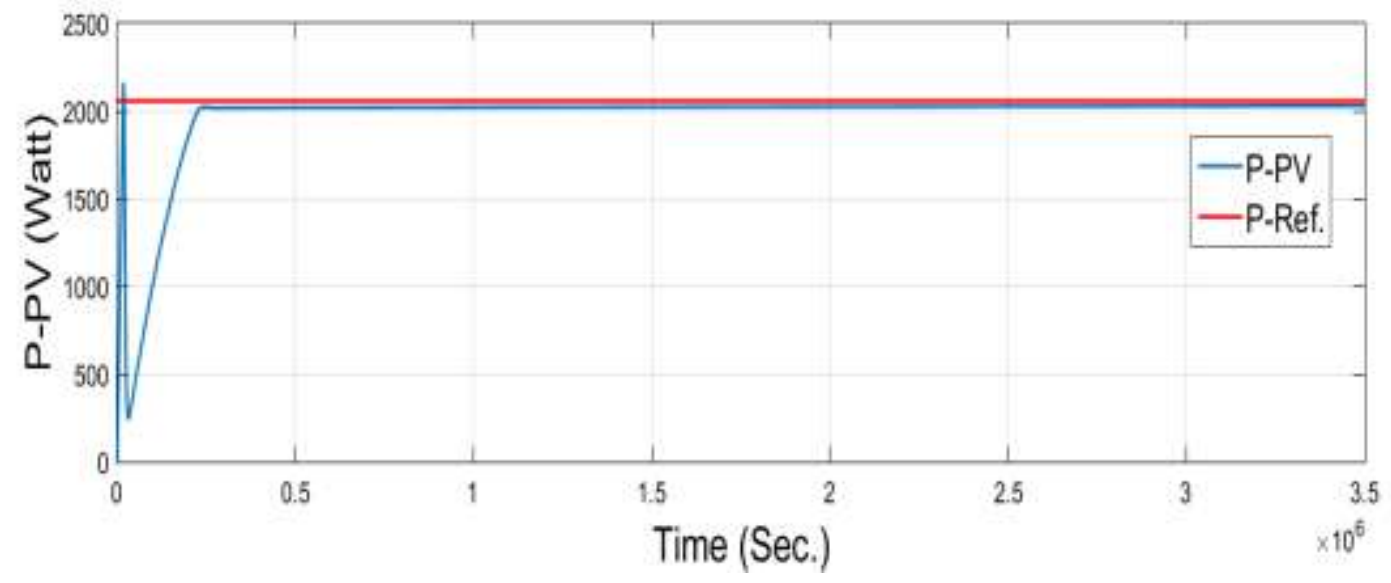

Fig.22: P-PV (2030W)

Reference Power is 2058 watt while the Simulated power is 2030watt (with error=1.4\%)

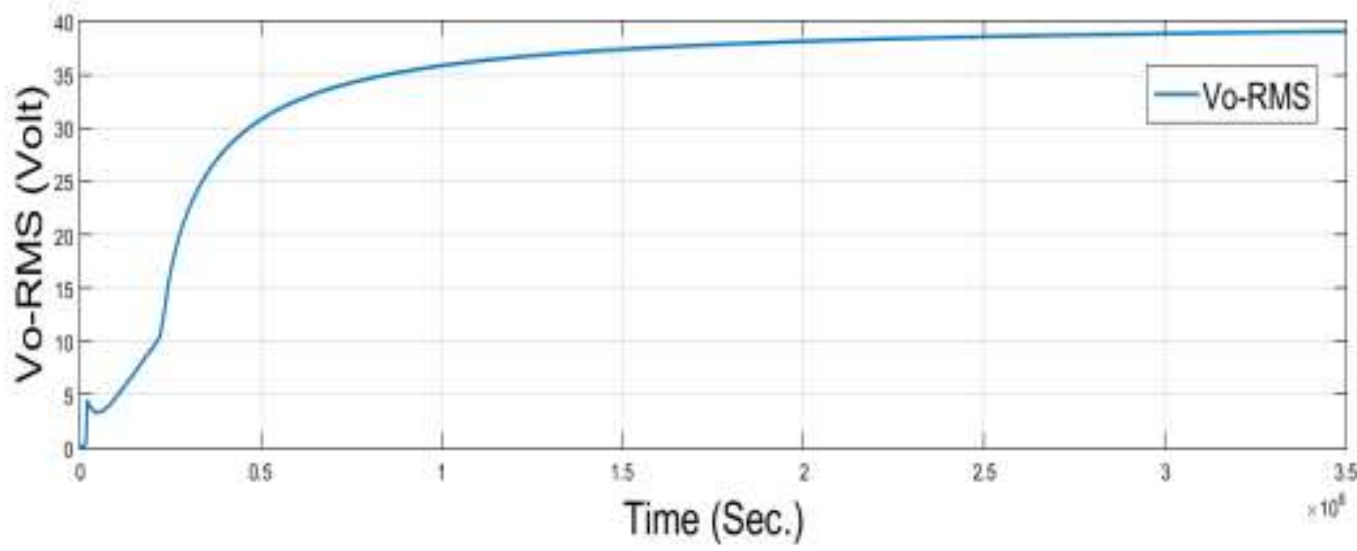

Fig.23: Vo-RMS

Vo-RMS is $\approx(38 \mathrm{~V})$ 


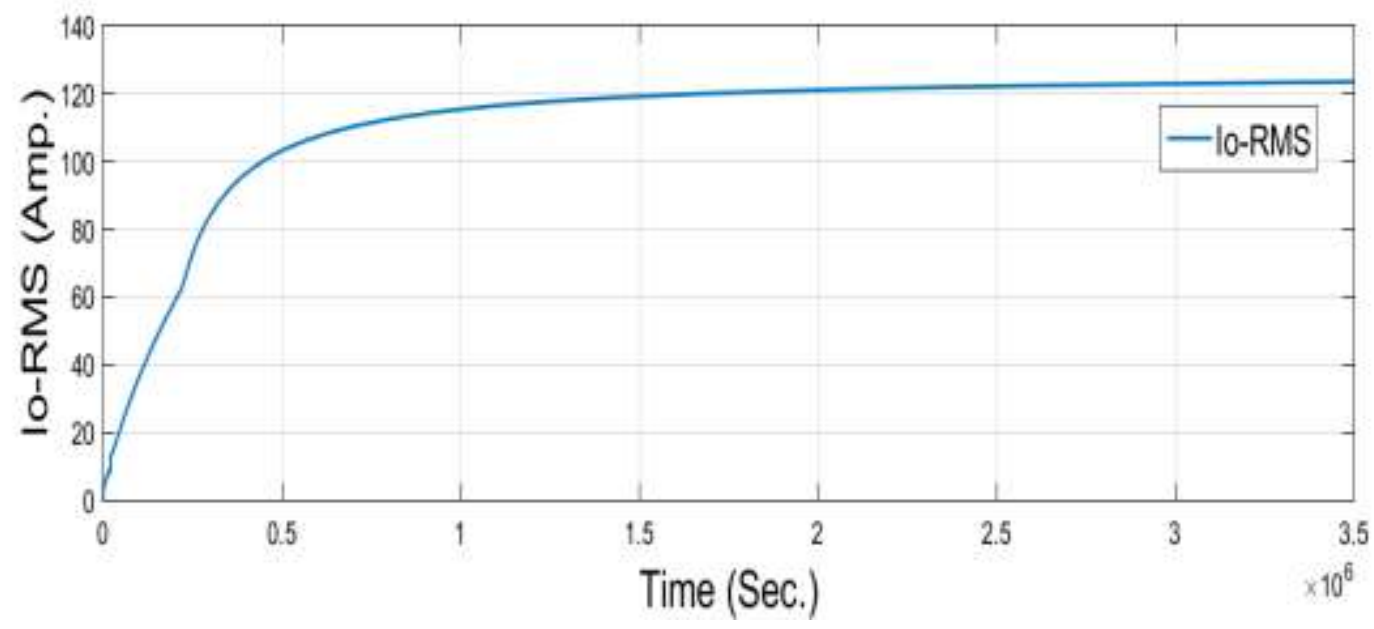

Fig.24: Io-RMS

Io-RMS is $\approx(124 A)$

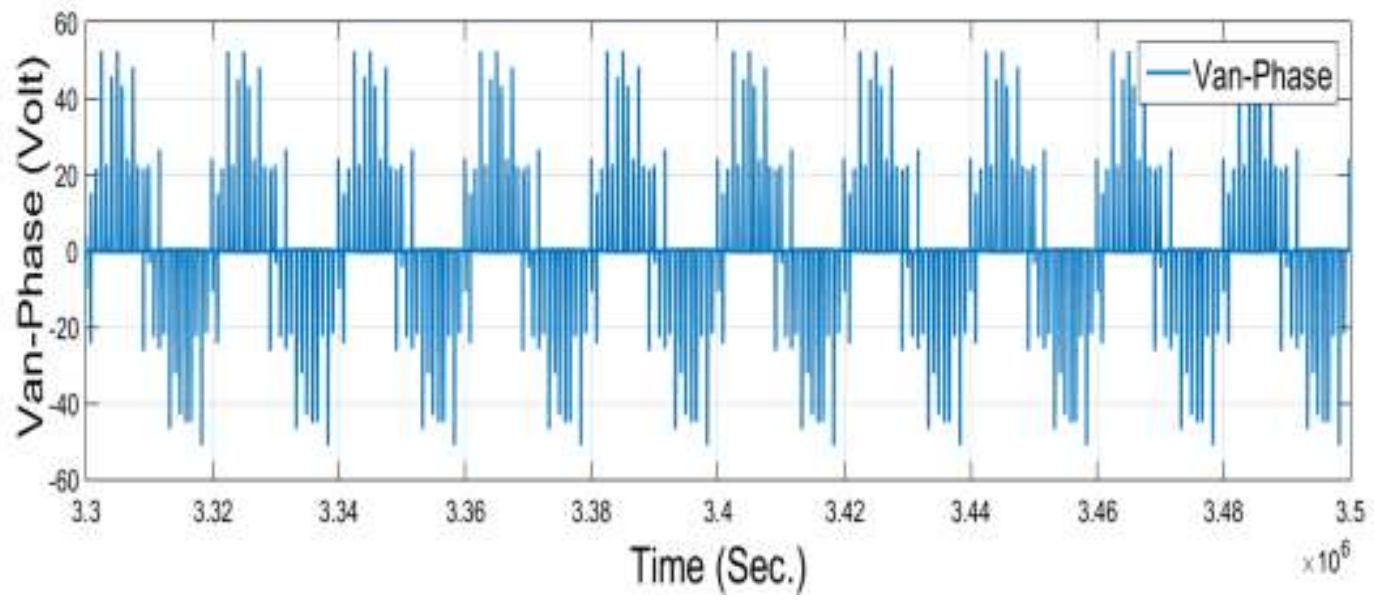

Fig.25: Van-Phase Volt

Van is $\approx(50 \mathrm{~V})$

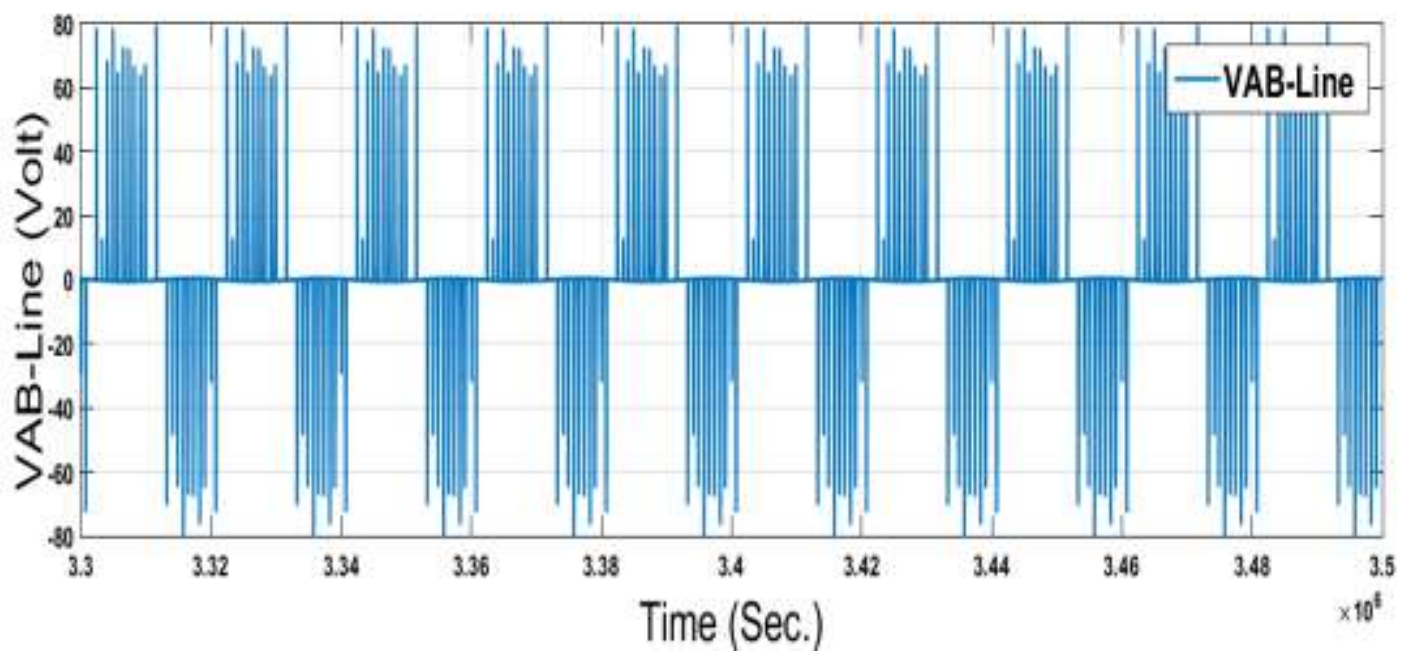

Fig.26: VAB-Line Voltage

VAB-Line Volt is $\approx(70 \mathrm{~V})$ 


\subsection{Case Study (2) : Temp. $40{ }^{\circ} \mathrm{C} \&$ Different Sudden change Irrad.}

In this case, Constant Temp $=40^{\circ} \mathrm{C}$ and Irradiance is sudden change as per the following:

TABLE 7. Change in Irradiance Vs Time

\begin{tabular}{|l|c|c|}
\hline Time From (Sec.) & Time To (Sec.) & $\begin{array}{c}\text { Irradiance } \\
\left(\mathrm{W} / \mathrm{m}^{2}\right)\end{array}$ \\
\hline 0 & 0.7 & 400 \\
\hline 0.7 & 1.5 & 1000 \\
\hline 1.5 & 2.5 & 600 \\
\hline 2.5 & 3.5 & 800 \\
\hline
\end{tabular}

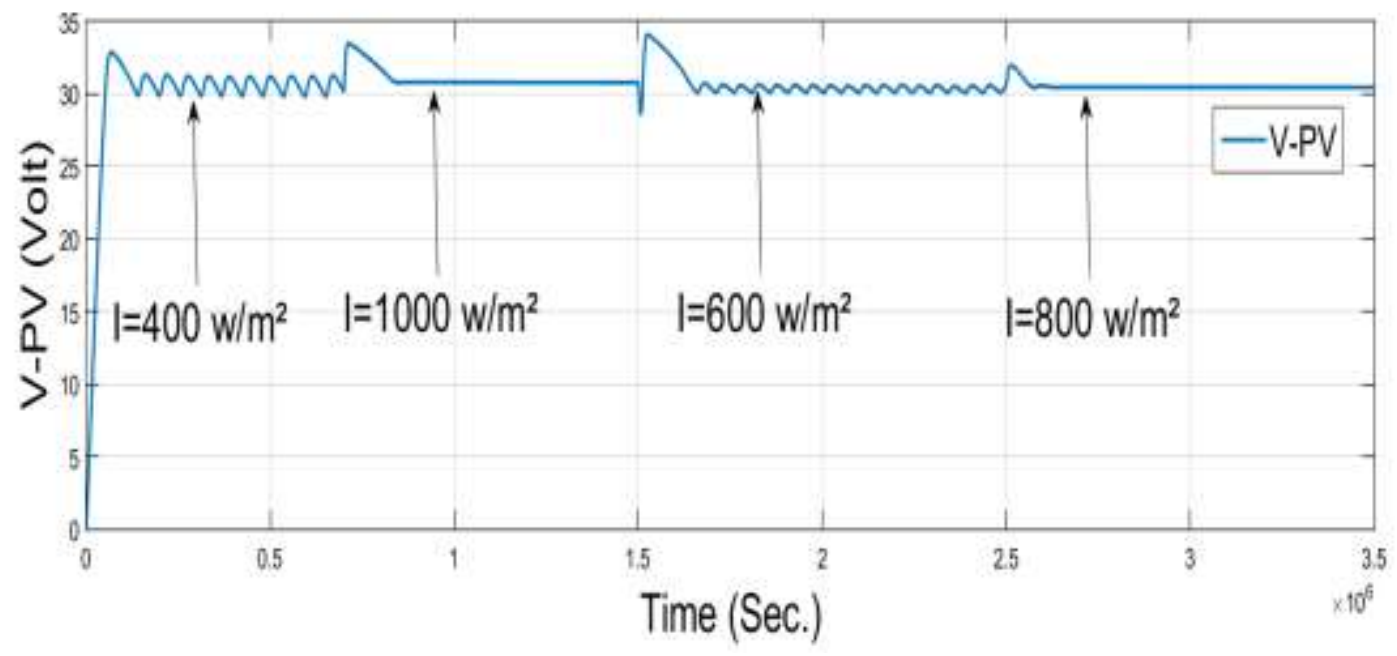

Fig.27 : V-PV for different Irrad. \& Temp. $=40{ }^{\circ} \mathrm{C}$

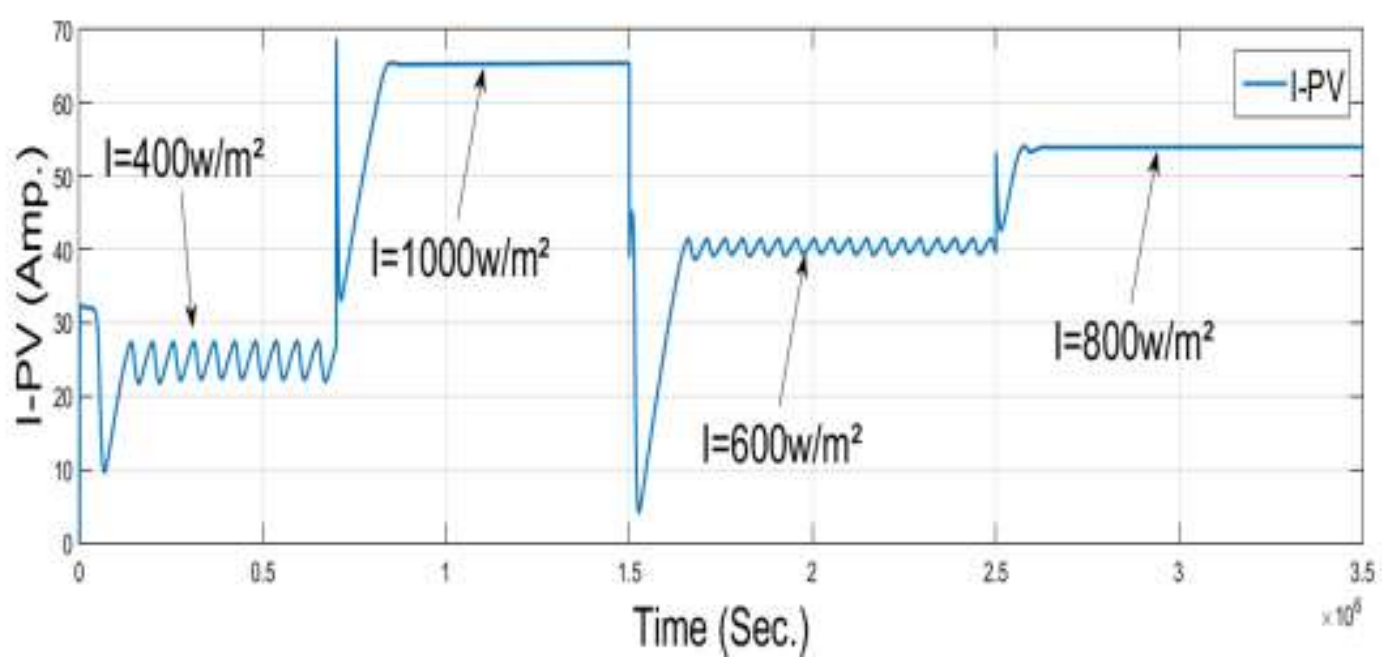

Fig.28 : I-PV for different Irrad. \& Temp. $=40^{\circ} \mathrm{C}$ 


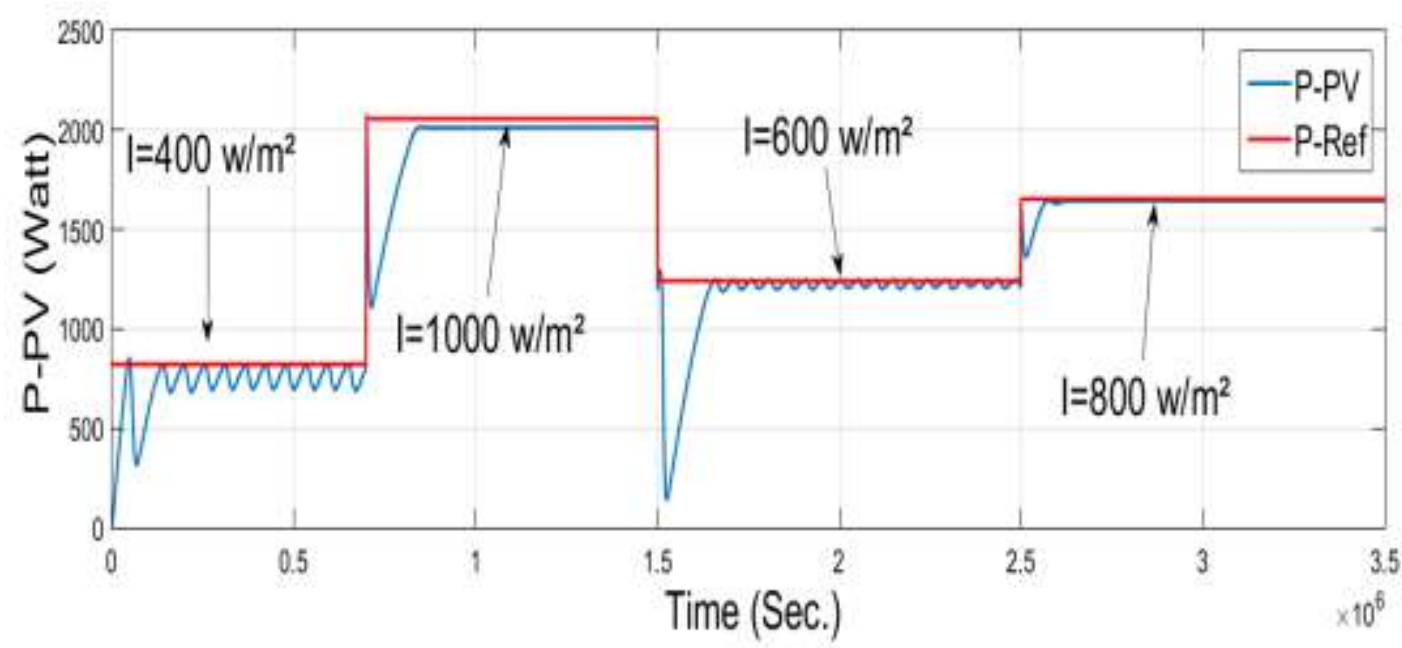

Fig.29 : P-PV for different Irrad. \& Temp. $=40^{\circ} \mathrm{C}$

As shown in Fig.29, In first Section $\left(\mathrm{I}=400 \mathrm{w} / \mathrm{m}^{2}\right)$ the reference power is 822.4 watt while the simulated power is $\approx 780$ watt with error $\approx \mathbf{5 \%}$

In Second Section $\left(I=1000 \mathrm{w} / \mathrm{m}^{2}\right)$ the reference power is 2058 watt while the simulated power is $\approx 2030$ watt with error $\approx \mathbf{1 . 3 6 \%}$

In Third Section $\left(\mathrm{I}=600 \mathrm{w} / \mathrm{m}^{2}\right)$ the reference power is 1242 watt while the simulated power is $\approx 1200$ watt with error $\approx \mathbf{3} \mathbf{3 . 3 8 \%}$

In Fourth and last Section $\left(\mathrm{I}=800 \mathrm{w} / \mathrm{m}^{2}\right)$ the reference power is 1654 watt while the simulated power is $\approx 1650$ watt with error $\approx \mathbf{0 . 2 4 \%}$

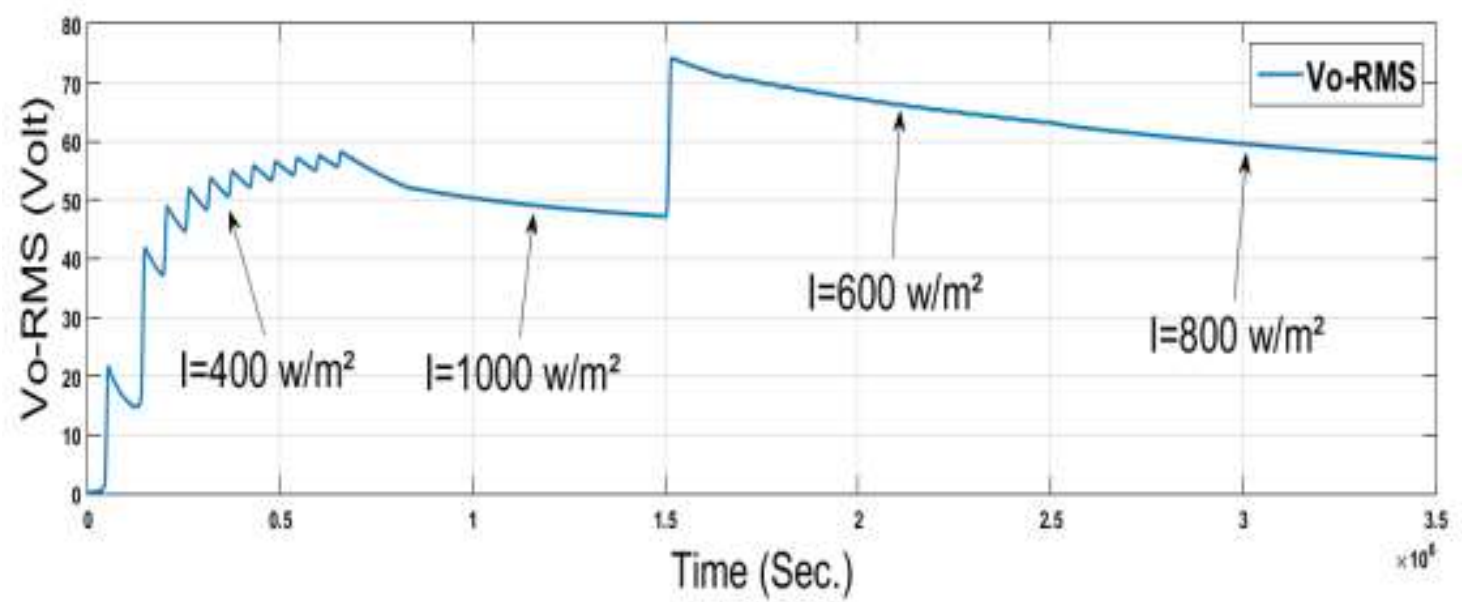

Fig.30 : Vo-RMS for different Irrad. \& Temp. $=40{ }^{\circ} \mathrm{C}$ 


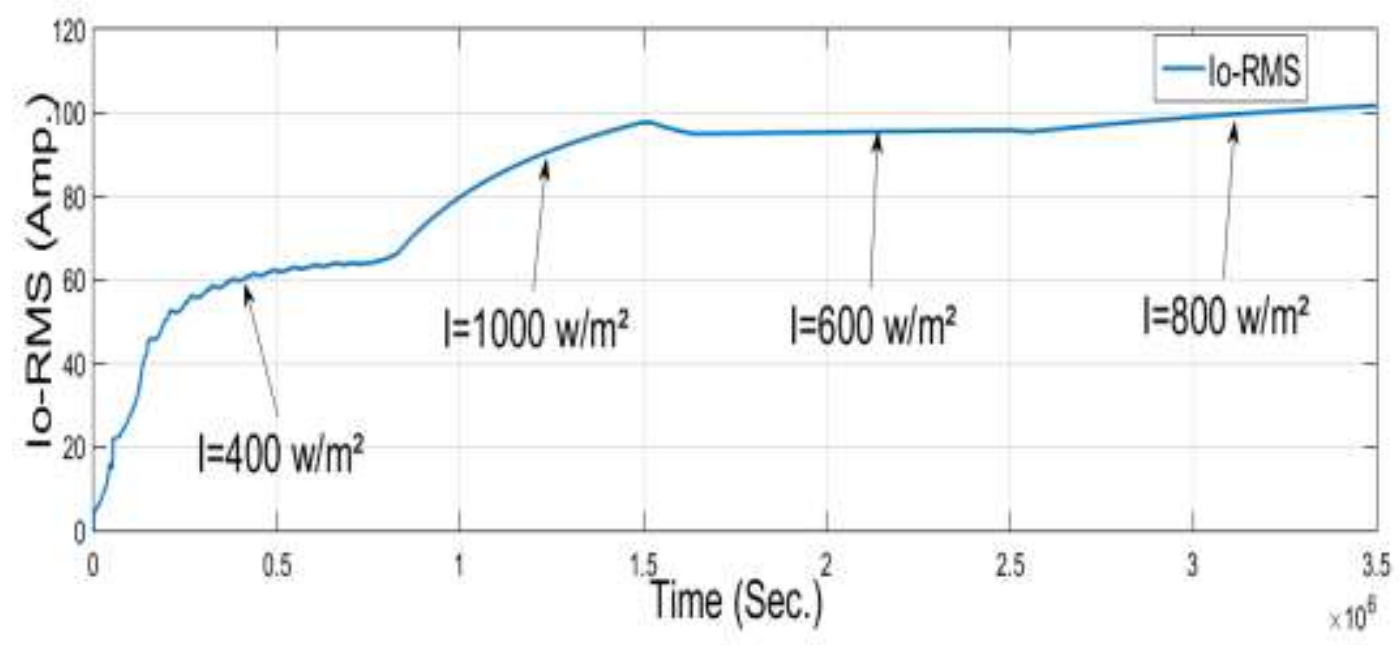

Fig.31 : Io-RMS for different Irrad. \& Temp. $=40{ }^{\circ} \mathrm{C}$

\section{- Phase Voltage :}

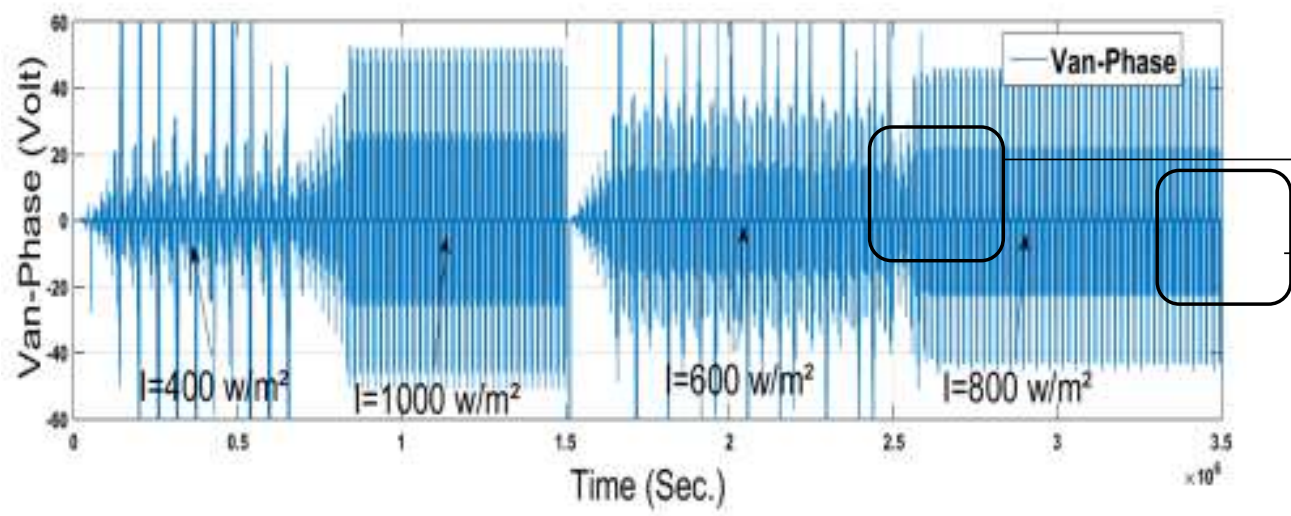

(a)

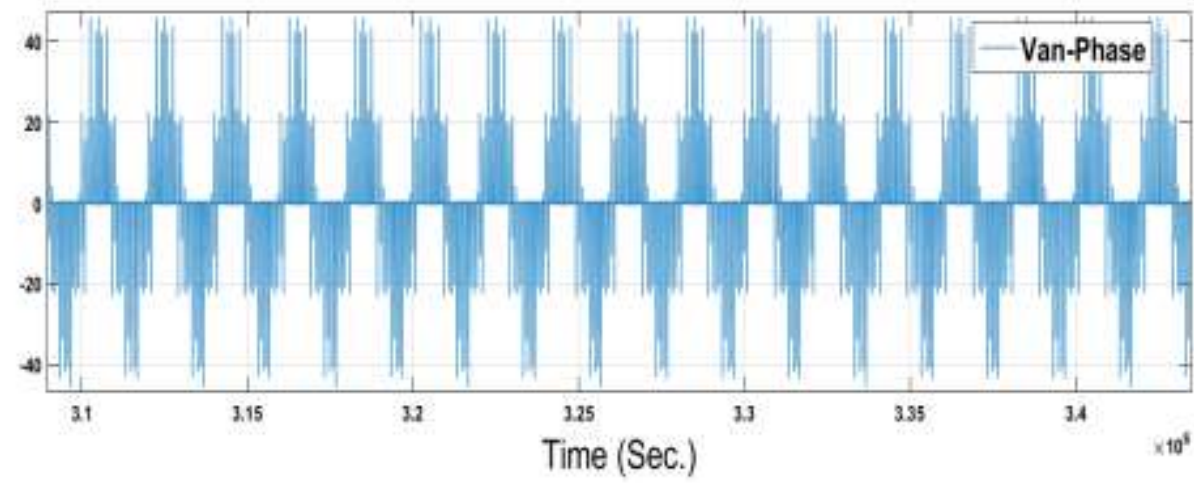

(b) 


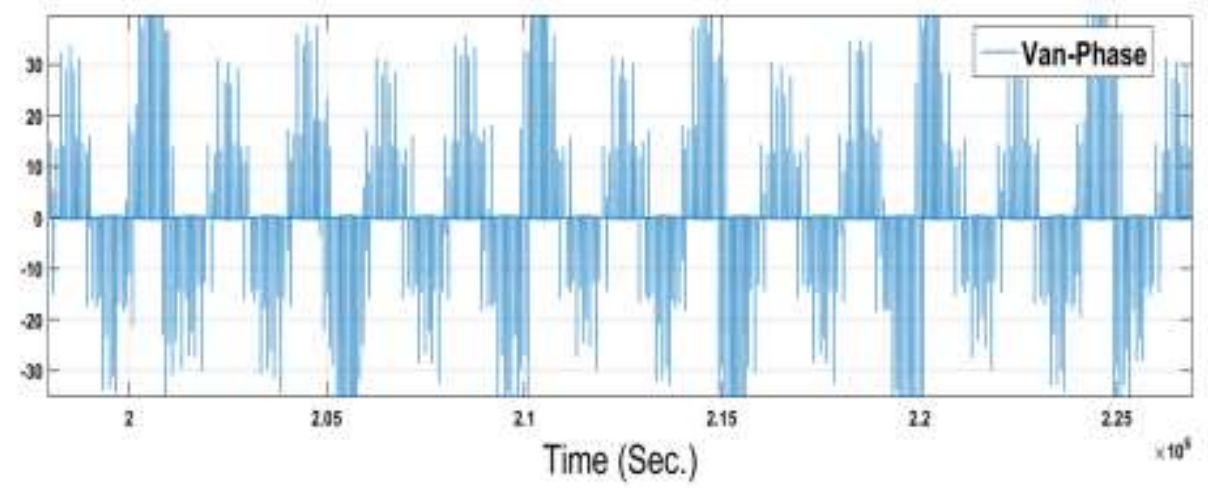

(c)

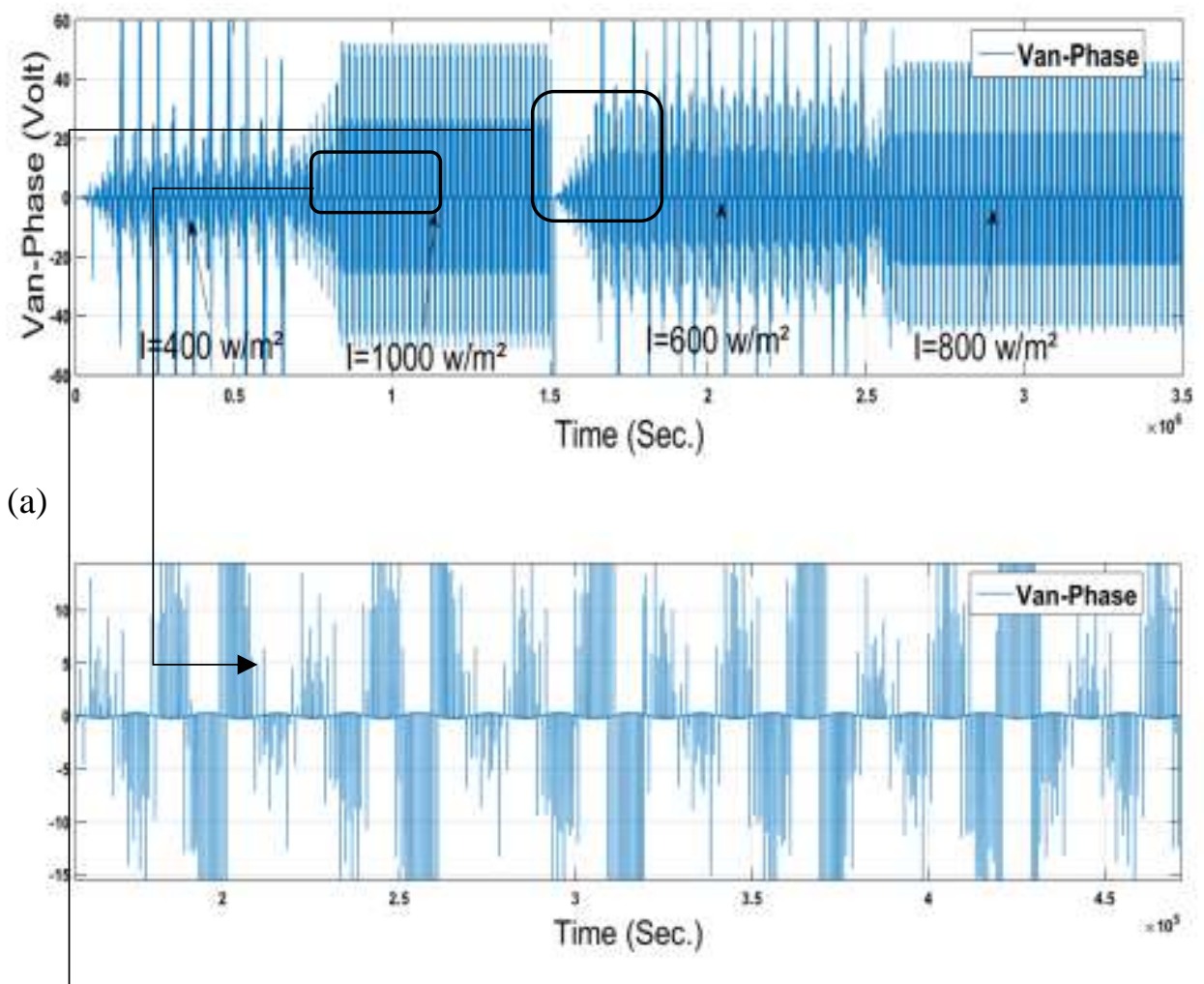

(d)

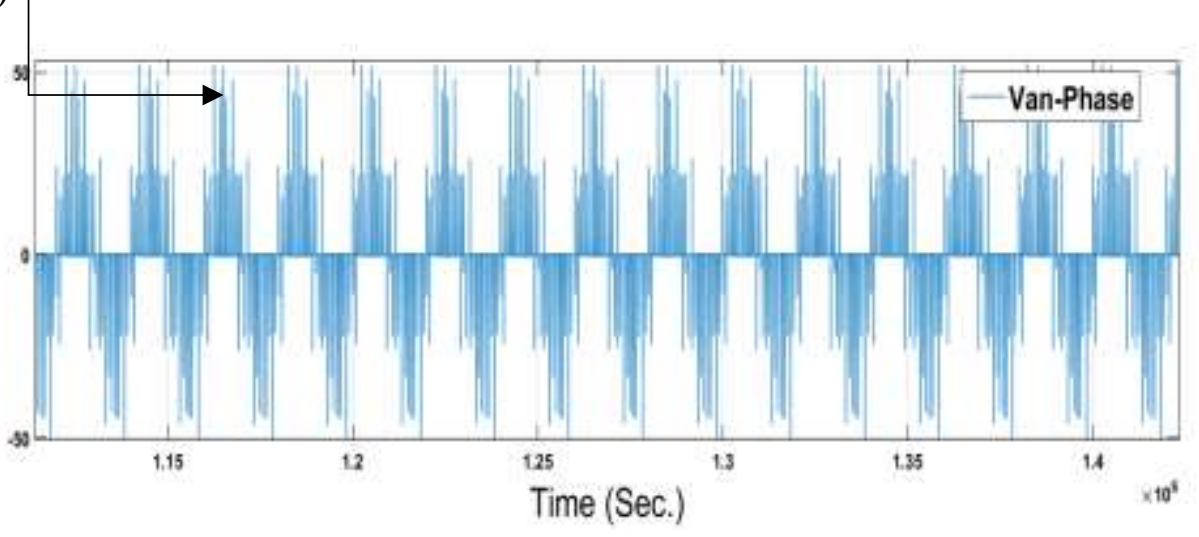

(e)

(a)Overall, (b) $I=800 \mathrm{w} / \mathrm{m}^{2}$, (c) $I=600 \mathrm{w} / \mathrm{m}^{2}$, (d) $I=400 \mathrm{w} / \mathrm{m}^{2}$, (e) $I=1000 \mathrm{w} / \mathrm{m}^{2}$

Fig. 32: Van-Phase Voltage for different Irrad. \& Temp. $=40^{\circ} \mathrm{C}$

Mohammed F. Gabr et al., IJAEBS (2021), (2), (1), (100-131)

10.21608/ijaebs.2021.69272.1008 


\section{- Line Voltage :}

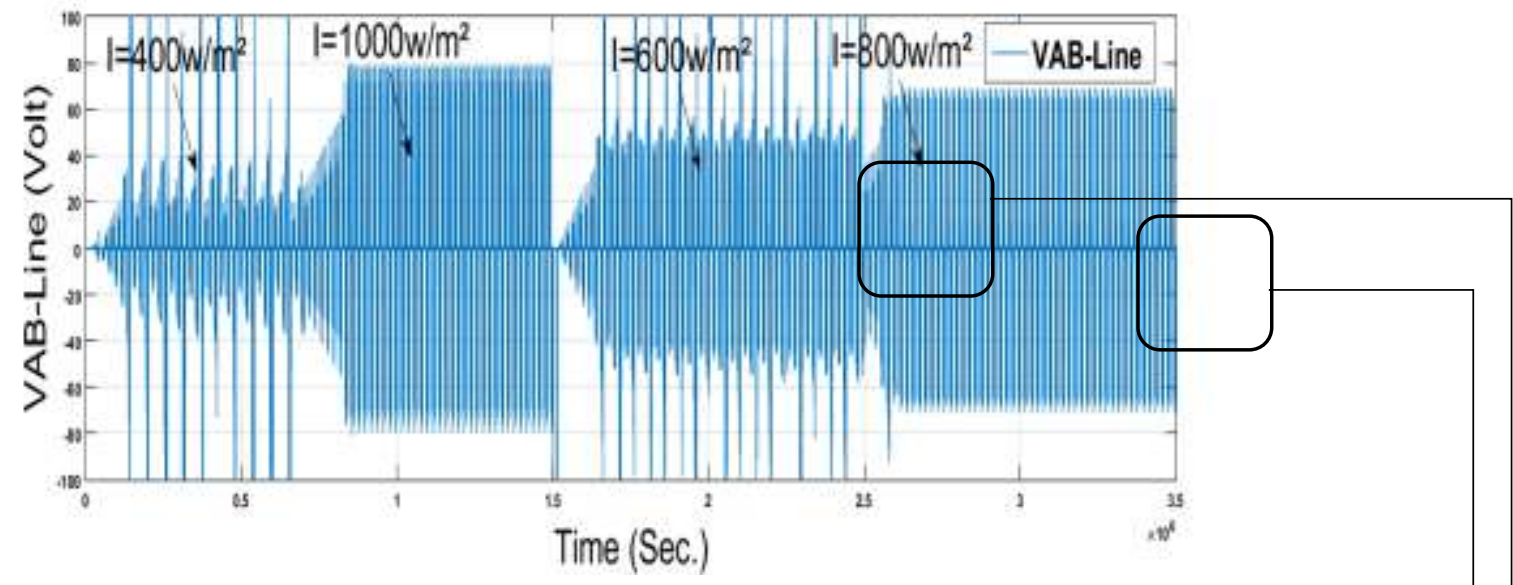

(a)

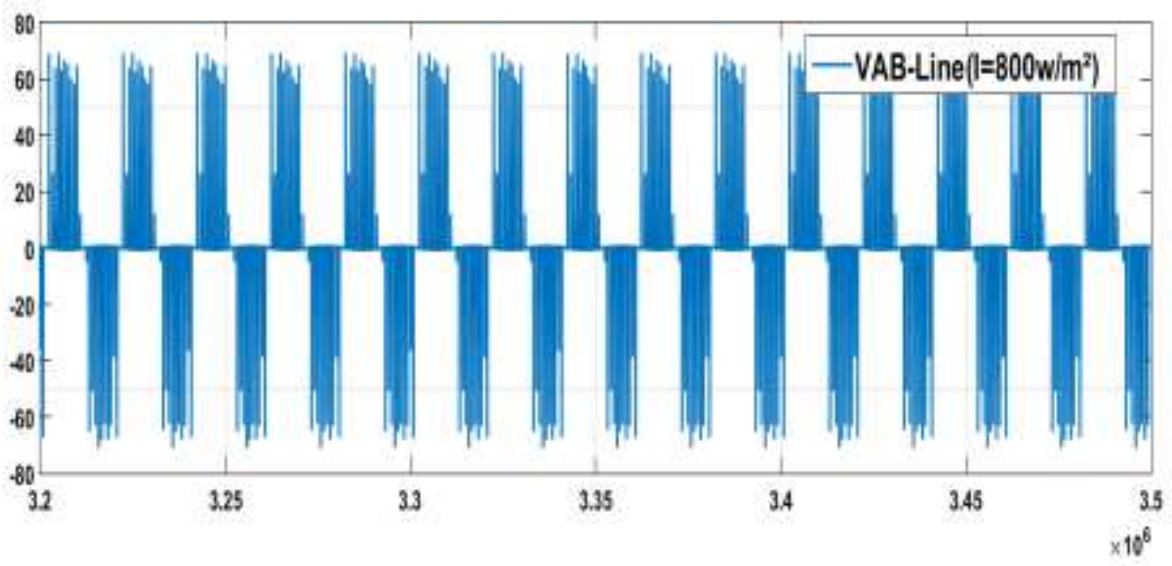

(b)

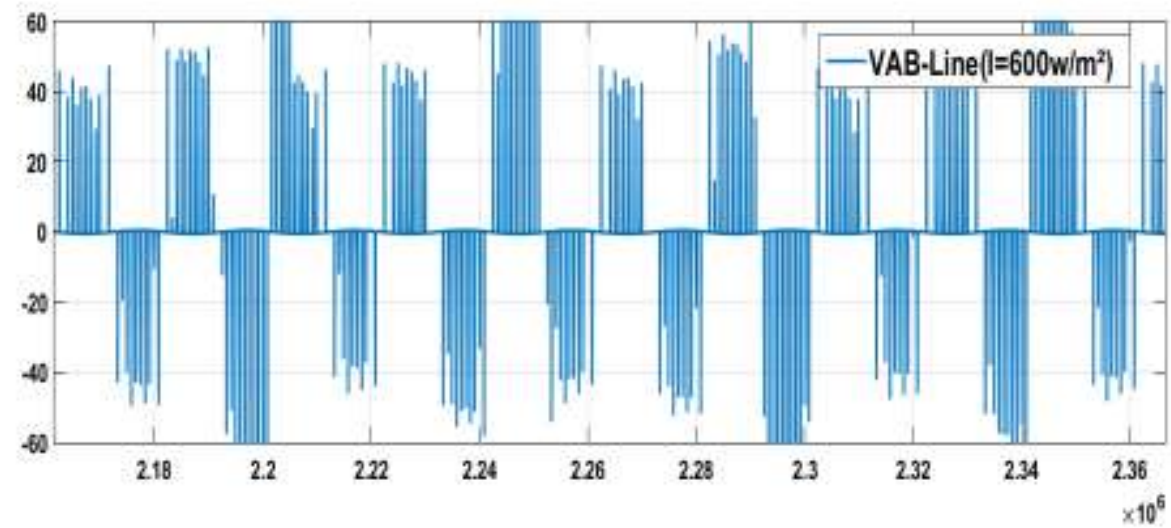

(c) 


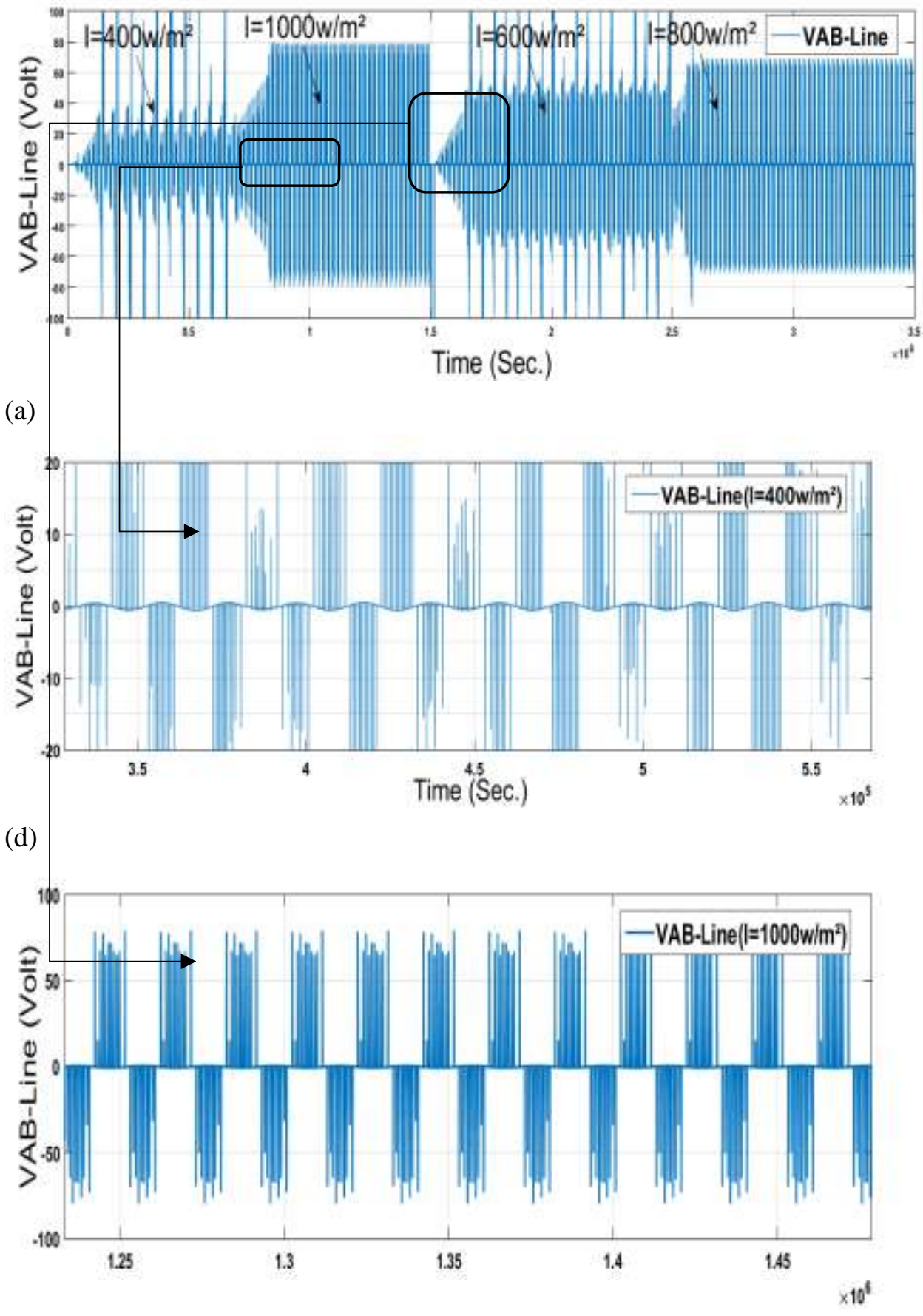

(e)

(a)Overall, (b) $\mathrm{I}=800 \mathrm{w} / \mathrm{m}^{2}$, (c) $\mathrm{I}=600 \mathrm{w} / \mathrm{m}^{2}$, (d) I=400w/m $\mathrm{m}^{2}$, (e) $\mathrm{I}=1000 \mathrm{w} / \mathrm{m}^{2}$

Fig.33 : VAB-Line Voltage for different Irrad. \& Temp. $=40{ }^{\circ} \mathrm{C}$ 


\section{CONCLUSION}

In this paper, a Deep detail of ANFIS and Grid Connected. Photovoltaic power generation system required an effective controller to overcome sudden irradiance change and to maximize their efficiency in order to be more efficient $\&$ more precise. This paper proposed an approach of MPPT based on a voltage control approach of power converter with the use of the Adaptive Fuzzy logic controller (Adaptive FLC). The input voltage reference is adaptively perturbed with variable steps until the maximum power is reached. A state-space model is derived through averaging method, with the control input being the modulation depth of the proposed Inverter. The proposed control scheme achieved stable condition in the control region of the PV panel and eliminated the steady state oscillations when there is sudden change of irradiance in the maximum power operating point. Furthermore, the PV system became more efficient, as proven by sudden change in radiation conditions for 0.2 seconds, where energy can be saved approximately 95\%. As the max error percentage (Kindly refer to Fig.29)

\section{ACKNOWLEDGMENT}

The authors would like to thank the MOHE (ministry of high education), Egypt - Faculty of Engineering, Helwan University (HU) Cairo, Egypt by using research for providing some facilities and others supporting to carry out this research .

\section{REFERENCES}

[1] Milovan Majstorovic, (2020).Implementation of MPPT Methods with SEPIC Converter, DOI:10.1109/INFOTEH48170.2020.9066296

[2] Sivakumar Selvam, (2020). An Adaptive Resistance Perturbation Based MPPT Algorithm for PhotovoltaicApplications, IEEE Trans ,DOI: 10.1109/ACCESS.2020.3034283

[3] MeriemOurahou, (2020). Comparative study of the MPPT control algorithms for photovoltaic panel,Proceedings of the International Conference on Industrial Engineering and Operations ManagementRabat, Morocco, April 11-13, 2017.

[4] International Journal of Electrical and Computer Engineering (IJECE), (2020). A modified particle swarm optimization algorithm to enhanceMPPT in the PV array. ISSN: 2088-8708, DOI: 10.11591/ijece.v10i5.pp5001-5008.

[5] ŽarkoZecevi'cand Maja Rolevski ,(2020).Neural Network Approach to MPPT Control and Irradiance Estimation, Appl. Sci. 2020, 10, 5051; doi:10.3390/app10155051.

[6] Md Tofael Ahmed, (2020). Non-iterative MPPT Method: A Comparative Study ,international journal of renewable energy research Ahmed et al., Vol.10, No.2, June, 2020.

[7] Bennacer el Hassouni, (2020). A Study Of Efficient MPPT Techniques For Photovoltaic SystemUsing Boost Converter. Paper Submitted to ICEREGA'17

[8] Tariq Iqbal, (2020). Simulation and Hardware Implementation of a MPPT Charge Controller for a Photovoltaic Systems. Conference Paper.December 2020 
[9] Mohamed Regad,M'hamedHelaimi, Rachid Taleb,Ahmed M. Othman and Hossam A. Gabbar, (2020). Control of hybrid power system based renewable energygenerations using PID controller. ISSN: 2088-8694, DOI: 10.11591/ijpeds.v11.i4.pp1775-1784

[10] MeryemBachar and Ahmed Naddami (2020). Simulation and Implementation of a Modified ANFIS MPPT Technique. Advances in Technology Innovation, vol. 5, no. 4, 2020, pp. 230-247.

[11]FuminoriKobayashi ,SlametKasbi and Rasli A Ghani (2018). A New Approach of Maximum Power Point Tracking Technique for Sudden Change of Irradiance in Photovoltaic Systems .Journal of Computational and Theoretical Nanoscience

[12]Zadeh. L.A, Fuzzy sets, Information and Control, Vol. 8, pp. 338-353. 1965.

[13] Mamdani E. H, Application of fuzzy algorithms for the control of a dynamic plant, Proceedings of IEEE, 1974, Vol 121, pp. 1585-1588.

[14] Li. Shuhui, Haskew, Li Dawen and Fei Hu, "Integrating photovoltaic and power converter characteristics for energy extraction study of solar PV systems ", Renewable Energy, Dec 2011, Vol. 36, Issue 12, pp. 3238-3245.

[15] Chandani Sharma, Anamika Jain, 'erformance Comparison of PID and Fuzzy Controllers in Distributed MPPT " , International Journal of Power Electronics and Drive System (IJPEDS) Vol. 6, No. 3, September 2015, pp. 625 635 ISSN: 2088-8694

[16] A. Reaz Reisi, A. Alidousti, Optimal Designing Grid-Connected PV Systems (Intech Open, Rijeka, 2019).

[17] Y. Abdalla, I. Farog, Y. Mamoun, Grid connected photovoltaic system, in International

Conference on Communication, Control,Computing and Electronics Engineering (ICCCCEE)(IEEE, 2017), pp. 1-5

[18] R. Kadri, J. Gaubert, G. Champenois, An improved maximum power point tracking for photovoltaic grid- connected inverter based on voltage-oriented control. IEEE Trans. Industr.

Electron. 58(1), 66-75 (2010) 